\title{
Infrared spectra and optical constants of astronomical ices: III. Propane, propylene, and propyne
}

Article

Accepted Version

Creative Commons: Attribution-Noncommercial-No Derivative Works 4.0

Hudson, R. L., Gerakines, P. A., Yarnall, Y. Y. and Coones, R.

T. ORCID: https://orcid.org/0000-0001-6651-4707 (2021)

Infrared spectra and optical constants of astronomical ices: III. Propane, propylene, and propyne. Icarus, 354. 114033. ISSN 0019-1035 doi: https://doi.org/10.1016/j.icarus.2020.114033 Available at https://centaur.reading.ac.uk/92469/

It is advisable to refer to the publisher's version if you intend to cite from the work. See Guidance on citing.

Published version at: http://dx.doi.org/10.1016/j.icarus.2020.114033

To link to this article DOI: http://dx.doi.org/10.1016/j.icarus.2020.114033

Publisher: Elsevier

All outputs in CentAUR are protected by Intellectual Property Rights law, including copyright law. Copyright and IPR is retained by the creators or other copyright holders. Terms and conditions for use of this material are defined in the End User Agreement.

www.reading.ac.uk/centaur 
Central Archive at the University of Reading

Reading's research outputs online 
Infrared Spectra and Optical Constants of Astronomical Ices:

III. Propane, Propylene, and Propyne

\author{
by
}

Reggie L. Hudson ${ }^{a}$, Perry A. Gerakines ${ }^{a}$, Yukiko Y. Yarnalla,b, and Ryan Coones ${ }^{a, c}$

a Astrochemistry Laboratory, NASA Goddard Space Flight Center, Greenbelt, MD 20771, USA

b Universities Space Research Association, Greenbelt, Maryland 20771, USA

c School of Pharmacy, University of Reading, Whiteknights, Reading, RG6 6AD, UK

Proposed Running Head: IR Spectra of Propane, Propylene, and Propyne Ices

Editorial correspondence and proofs to be directed to:

Reggie L. Hudson

Astrochemistry Laboratory (Code 691)

NASA Goddard Space Flight Center

Greenbelt, MD 20771

reggie.hudson@nasa.gov

Phone: (301) 286-6961

Manuscript pages: 39 pages (includes figures and tables)

Tables: 9

Figures: 14 


\begin{abstract}
Infrared (IR) spectra of the hydrocarbon ices $\mathrm{C}_{3} \mathrm{H}_{8}$ (propane), $\mathrm{C}_{3} \mathrm{H}_{6}$ (propylene, propene), and $\mathrm{C}_{3} \mathrm{H}_{4}$ (propyne, methylacetylene) are relevant to the study of the lowtemperature chemistry and spectroscopy of objects within and beyond the Solar System, but IR band strengths and absorption coefficients are lacking for these compounds. Here we present new IR spectra of crystalline and non-crystalline forms of $\mathrm{C}_{3} \mathrm{H}_{8}, \mathrm{C}_{3} \mathrm{H}_{6}$, and $\mathrm{C}_{3} \mathrm{H}_{4}$. Measurements of ice density and refractive index also are reported, two quantities needed to compute IR absorption coefficients, band strengths, optical constants, and, ultimately, abundances of propane, propylene, and propyne in extraterrestrial environments and in laboratory experiments. Suggestions and interpretations are made regarding the multiple crystalline forms of propane and propylene observed. Applications and extensions are described.
\end{abstract}

Key Words: Ices, IR spectroscopy, TNOs, Titan, organic chemistry, infrared observations 


\section{Introduction}

Several years ago we reported infrared (IR) optical constants of three 2-carbon hydrocarbon ices, acetylene $\left(\mathrm{C}_{2} \mathrm{H}_{2}\right)$, ethylene $\left(\mathrm{C}_{2} \mathrm{H}_{4}\right)$, and ethane $\left(\mathrm{C}_{2} \mathrm{H}_{6}\right)$, presenting data for amorphous and crystalline forms of each compound (Hudson et al., 2014a; Hudson et al., 2014b). We also presented apparent and absolute IR band strengths, as well as apparent and absolute absorption coefficients, for the solids forms of these compounds known to exist under vacuum conditions. The applications of such data are to laboratory work and observational astronomy, both ground-based and space based. Studies of the chemistry of worlds on which solid hydrocarbons exist, such as Pluto, Titan, and trans-Neptunian objects (TNOs), can benefit from our results in the quantification of ice composition (e.g., Brown et al., 2015; Sasaki et al., 2005). Similarly, laboratory studies of the reaction chemistry of small molecules of planetary and interstellar interest find our work relevant for measuring molecular abundances and reaction yields (e.g., Dartois et al., 2017; Fleury et al., 2019; Behmard et al., 2019).

The astrochemical background and justification for our particular choice of hydrocarbons to study is straightforward and does not need extensive comment. Aliphatic hydrocarbon compounds of the type $\mathrm{C}_{3} \mathrm{H}_{\mathrm{x}}(\mathrm{x}=1,2,3)$ are found in a variety of astronomical environments and are suspected in others. Propane $\left(\mathrm{C}_{3} \mathrm{H}_{8}, \mathrm{H}_{3} \mathrm{C}-\mathrm{CH}_{2}-\mathrm{CH}_{3}\right)$ is known to be both meteoritic and a component of Titan's atmosphere (Maguire et al., 1981; Sephton et al. 2001; Roe et al., 2003). Propylene $\left(\mathrm{C}_{3} \mathrm{H}_{6}, \mathrm{H}_{2} \mathrm{C}=\mathrm{CH}-\mathrm{CH}_{3}\right)$ also is a Titan molecule, and has been detected in the interstellar medium as well (Marcelino et al., 2007; Nixon et al., 2013). Propyne $\left(\mathrm{C}_{3} \mathrm{H}_{4}, \mathrm{HC} \equiv \mathrm{C}-\mathrm{CH}_{3}\right)$ is, again, found at Titan and is interstellar (Snyder and Buhl, 1973; Teanby et al. 2009). Given the presence of methane $\left(\mathrm{CH}_{4}\right)$ and ethane $\left(\mathrm{C}_{2} \mathrm{H}_{6}\right)$ on Pluto's surface (Cruikshank et al., 2015), and the known tendency for solid $\mathrm{CH}_{4}$ to yield more-complex hydrocarbons upon ion irradiation, these same three $\mathrm{C}_{3} \mathrm{H}_{x}$ molecules are expected on that world and other TNOs (e.g., Strazzulla et al. 1984; Baratta et al., 2003; Bennett et al., 2006; Hudson et al., 2009). Added to these examples of Solar System hydrocarbons are reports of aliphatic organics, or aliphatic functional groups, on lapetus, Ceres, and comet 67P (Cruikshank et al., 2014; De Sanctis et al., 2017; Raponi et al., 2020). In some cases, $\mathrm{C}_{3} \mathrm{H}_{\mathrm{x}}$ molecules already are known to exist in the gas phase, but they also are suspected in the solid phase where they can undergo reactions to produce both simpler and morecomplex chemical species.

The laboratory background and justification for our work is somewhat more convoluted. About 20 years ago our group published a study of cometary hydrocarbons, including propane, formed by ionizing radiation (Moore and Hudson, 1998). An IR band strength given there for propane in an $\mathrm{H}_{2} \mathrm{O}$-ice was measured in a reflection mode for our spectrometer's optical path. That propane band-strength value has since been used in at least three other investigations, each involving transmission spectroscopy for which our value is not necessarily applicable (de Barros et al., 2011; Mejía et al., 2013; Vasconcelos et al., 2017). A paper from yet a different group described the photochemical formation of propane from solid $\mathrm{CH}_{4}$, but again a direct 
measure of an IR band strength for solid-propane was not available from which to calculate propane yields (Gerakines et al. 1996). The situation is different for propylene and propyne in the sense that no laboratory on these solids are available at all.

In the present paper we address these issues by continuing our earlier studies, now reporting new laboratory measurements of the IR intensities and optical constants of three 3-carbon solid hydrocarbons, propane $\left(\mathrm{C}_{3} \mathrm{H}_{8}\right)$, propylene $\left(\mathrm{C}_{3} \mathrm{H}_{6}\right.$, also called propene), and propyne $\left(\mathrm{C}_{3} \mathrm{H}_{4}\right.$, also called methyl acetylene). Results for both the amorphous and crystalline forms of each compound are presented, including the first IR intensity information for each solid, the first tabulation of peak positions for the metastable crystalline phases of $\mathrm{C}_{3} \mathrm{H}_{8}$ and $\mathrm{C}_{3} \mathrm{H}_{6}$, and reference solid-phase refractive index and density measurements. Our IR spectra and optical constants are presented both graphically and in electronic form to better facilitate their use.

Our choice of the mid-infrared region for this study is based on the large amount of earlier IR work in this spectral region and the ready ability mid-IR spectra offer for distinguishing and characterizing various solid forms of a compound and the transitions between them. Applications of our results to astronomical observational are possible, but we caution that our ices are not strictly analogs of those in any particular astronomical environment. However, using our results for reference, one can prepare ice mixtures with accurately known compositions either of several hydrocarbons or solid mixtures rich in $\mathrm{H}_{2} \mathrm{O}$-ice or frozen $\mathrm{N}_{2}$.

\section{Laboratory Procedures}

The laboratory methods and equipment used were largely the same as in our studies of acetylene, ethylene, and ethane (Hudson et al., 2014a; Hudson et al., 2014b), so only a summary is given here with an emphasis on new procedures. Propane, propylene, and propyne were purchased from Sigma Aldrich (now MilliporeSigma) with stated purities of $\geq 99 \%$ and used as received. Following some exploratory work to identify crystallization temperatures, we used an ultrahigh-vacuum (UHV) system $\left(\sim 10^{-10}\right.$ torr $)$ to measure densities and reference refractive indices $(\lambda=670 \mathrm{~nm})$ for both amorphous and crystalline forms of each compound, each quantity measured in triplicate or more. The phase or form of each sample was checked with an interfaced Thermo iS50 IR spectrometer. An INFICON quartz-crystal microbalance enabled density measurements to be made during the growth of each ice sample, while twolaser interferometry gave data from which each ice's refractive indices at $670 \mathrm{~nm}$ were determined (Tempelmeyer \& Mills, 1968; Hudson et al., 2017).

Briefly, for IR intensity measurements hydrocarbon ices were made by vaporphase deposition onto a pre-cooled $\mathrm{Csl}$ or $\mathrm{KBr}$ substrate $\left(\mathrm{T}_{\min } \sim 8 \mathrm{~K}\right)$. Transmission IR spectra were recorded at the deposition temperature and after various warmings and coolings. Deposition rates were such as to give an increase in ice thickness of a few micrometers per hour, as measured by laser interferometry. The spectrometer's IR beam was directed perpendicular to each ice sample, with spectra recorded from 7800 
to $400 \mathrm{~cm}^{-1}$ at a resolution of $0.5 \mathrm{~cm}^{-1}$ and 200 scans per spectrum. Higher resolutions could have been employed, but IR features were sufficiently broad that higher resolution carried little, if any, advantage. The focus of this paper is almost entirely on the 5000 to $400 \mathrm{~cm}^{-1}$ region, with longer and shorter wavenumbers (and wavelengths) to be studied later with somewhat thicker samples. Unlike in some of our previous work, no evidence of crystallization was seen on deposition near $10 \mathrm{~K}$ (e.g., Takeda et al., 1990; Hudson et al., 2014a; Hudson et al., 2014b; Mizuno et al., 2016).

Ices of various thicknesses were made from $\mathrm{C}_{3} \mathrm{H}_{8}, \mathrm{C}_{3} \mathrm{H}_{6}$, and $\mathrm{C}_{3} \mathrm{H}_{4}$, in order to evaluate absorption coefficients of IR peaks and IR band strengths with the same method as in our recent papers using slopes of the appropriate Beer's Law plots (e.g., Hudson et al., 2014a). See also Hollenberg and Dows (1961).

The most significant change in the present work was an upgrade in the way we calculated optical constants $n$ and $k$. The method used in our earlier hydrocarbon studies was updated, expanded, and incorporated into a newly developed computer program written in the Python language. Our code has the advantages of permitting wavenumber-dependent optical constants $n$ and $k$ of a substrate to be used, a stronger method for judging convergence, the ability to handle highly asymmetric IR bands that can be found with amorphous solids, and the ability to handle the very sharp features of crystalline ices. As there is no widely used, open-source software for optical-constants calculations, we intend to make ours publicly available (Gerakines and Hudson, 2020).

\section{Results}

\subsection{Refractive indices and densities}

A reference value of the refractive index of each of our ices was needed to measure ice thicknesses, which in turn were needed to determine absorption coefficients, band strengths, and optical constants. Calculations of the IR band strengths of an ice also required the ice's density. For the present study, the refractive index at $670 \mathrm{~nm}\left(n_{670}\right)$ and density $(\rho)$ of both crystalline and non-crystalline $\mathrm{C}_{3} \mathrm{H}_{8}, \mathrm{C}_{3} \mathrm{H}_{6}$, and $\mathrm{C}_{3} \mathrm{H}_{4}$ ices were measured in a UHV chamber ( $10^{-10}$ torr) with checks on $n_{670}$ in an older vacuum system ( $10^{-8}$ torr). Working with the UHV system was more expensive and slower than working with the older vacuum chamber, and little difference was found in the values of $n_{670}$ obtained. However, the UHV system had the great advantage of giving density values of ices. Such measurements of $n_{670}$ and $\rho$ for ices have been described in several publications, and in principle are straightforward albeit somewhat tedious. See Hudson et al. (2017) for more information, and Romanescu et al. (2010) and Luna et al. (2012) for examples from other laboratories.

Table 1 summarizes our measurements of the refractive index at $670 \mathrm{~nm}$ and density of crystalline and non-crystalline $\mathrm{C}_{3} \mathrm{H}_{8}, \mathrm{C}_{3} \mathrm{H}_{6}$, and $\mathrm{C}_{3} \mathrm{H}_{4}$ ices. Uncertainties (standard errors) are on the order of \pm 0.005 and $\pm 0.005 \mathrm{~g} \mathrm{~cm}^{-3}$ for $n_{670}$ and $\rho$, respectively. Density values are given only for the high-temperature stable crystalline 
phase of each ice investigated. Differences in $\rho$ among crystalline phases of each compound are expected to be only a few percent based on previous work with crystalline phases of $\mathrm{CH}_{3} \mathrm{CN}$ (Enjalbert and Galy, 2002), $\mathrm{CH}_{3} \mathrm{OH}$ (Torrie et al., 2002), $\mathrm{CH}_{4}$ (Bol'shutkin et al., 1971) and $\mathrm{H}_{2} \mathrm{O}$, $\mathrm{I}_{\mathrm{c}}$ and $\mathrm{ln}$ (Loerting et al., 2011).

\section{Table 1}

Refractive Indices and Densities of Three Hydrocarbon Ices ${ }^{a}$

\begin{tabular}{ccccccc}
\hline & \multicolumn{2}{c}{ Propane, $\mathrm{C}_{3} \mathrm{H}_{8}$} & \multicolumn{2}{c}{ Propylene, $\mathrm{C}_{3} \mathrm{H}_{6}$} & \multicolumn{2}{c}{ Propyne, $\mathrm{C}_{3} \mathrm{H}_{4}$} \\
Form & $n$ & $\rho / \mathrm{g} \mathrm{cm}^{-3}$ & $n$ & $\rho / \mathrm{g} \mathrm{cm}^{-3}$ & $n$ & $\rho / \mathrm{g} \mathrm{cm}^{-3}$ \\
\hline \multirow{2}{*}{ Amorphous } & 1.357 & 0.653 & 1.384 & 0.663 & 1.370 & 0.705 \\
& $(15 \mathrm{~K})$ & $(15 \mathrm{~K})$ & $(15 \mathrm{~K})$ & $(15 \mathrm{~K})$ & $(15 \mathrm{~K})$ & $(15 \mathrm{~K})$ \\
\multirow{5}{*}{ Crystalline } & 1.484 & 0.797 & 1.445 & 0.782 & 1.533 & 0.866 \\
& $(65 \mathrm{~K})$ & $(65 \mathrm{~K})$ & $(65 \mathrm{~K})$ & $(65 \mathrm{~K})$ & $(80 \mathrm{~K})$ & $(80 \mathrm{~K})$ \\
\hline
\end{tabular}

a Values of $n$ and $\rho$ are averages of at least three measurements

\subsection{Propane - infrared spectra}

When we began this study of $\mathrm{C}_{3}$ hydrocarbons, we were unable to find many publications, other than spectroscopic work, on solid propane or solid propylene. Two papers were particularly suggestive. First, Pavese and Besley (1981) identified two solid phases on cooling liquid propane, with one phase being substantially more stable than the other. Second, differential thermal analyses of both propane and propylene by Takeda et al. (1990), starting with a vapor-deposited amorphous solid in each case, clearly identified two crystallizations for each compound, each well below the sample's melting point. Combined with our earlier study (Hudson et al., 2014b) of the next smaller alkane and alkene (i.e., ethane and ethylene) and the two crystalline phases of each, we suspected that two crystalline phases might also be found in the present work on propane and propylene, and such was the case.

Infrared survey spectra of solid propane $\left(\mathrm{C}_{3} \mathrm{H}_{8}\right)$ are shown in Fig. 1. The sample giving the spectrum in (a) was made by vapor-phase deposition onto a substrate at $8 \mathrm{~K}$ under conditions that ensured that the resulting ice was amorphous in form. Warming to $40 \mathrm{~K}$ had little effect on the IR spectrum, but substantial irreversible changes took place on warming to $50 \mathrm{~K}$, followed by equally distinct irreversible changes on going to $60 \mathrm{~K}$. The survey spectra of Fig. 1 are useful for quickly seeing the relative intensities of IR peaks at these different temperatures over a broad range, but more details are seen in the expansions of Figs. 2 - 4 for the 3000 - 2800, 1500 - 1300, and $1200-700$ $\mathrm{cm}^{-1}$ regions, respectively. 


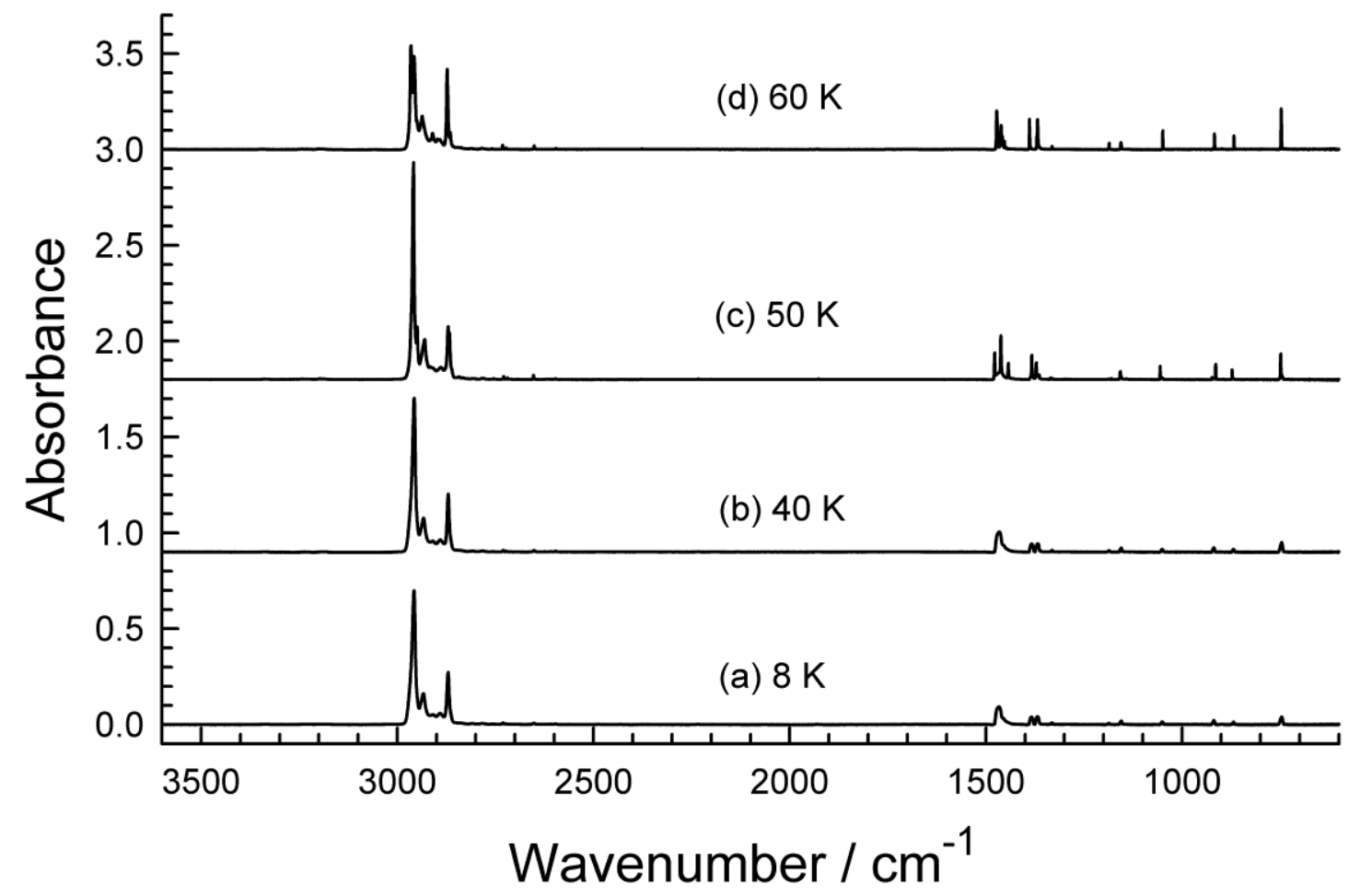

Fig. 1. Mid-IR survey spectra of $\mathrm{C}_{3} \mathrm{H}_{8}$ deposited at $8 \mathrm{~K}$ and warmed to the temperatures indicated. Spectra are offset for clarity. 


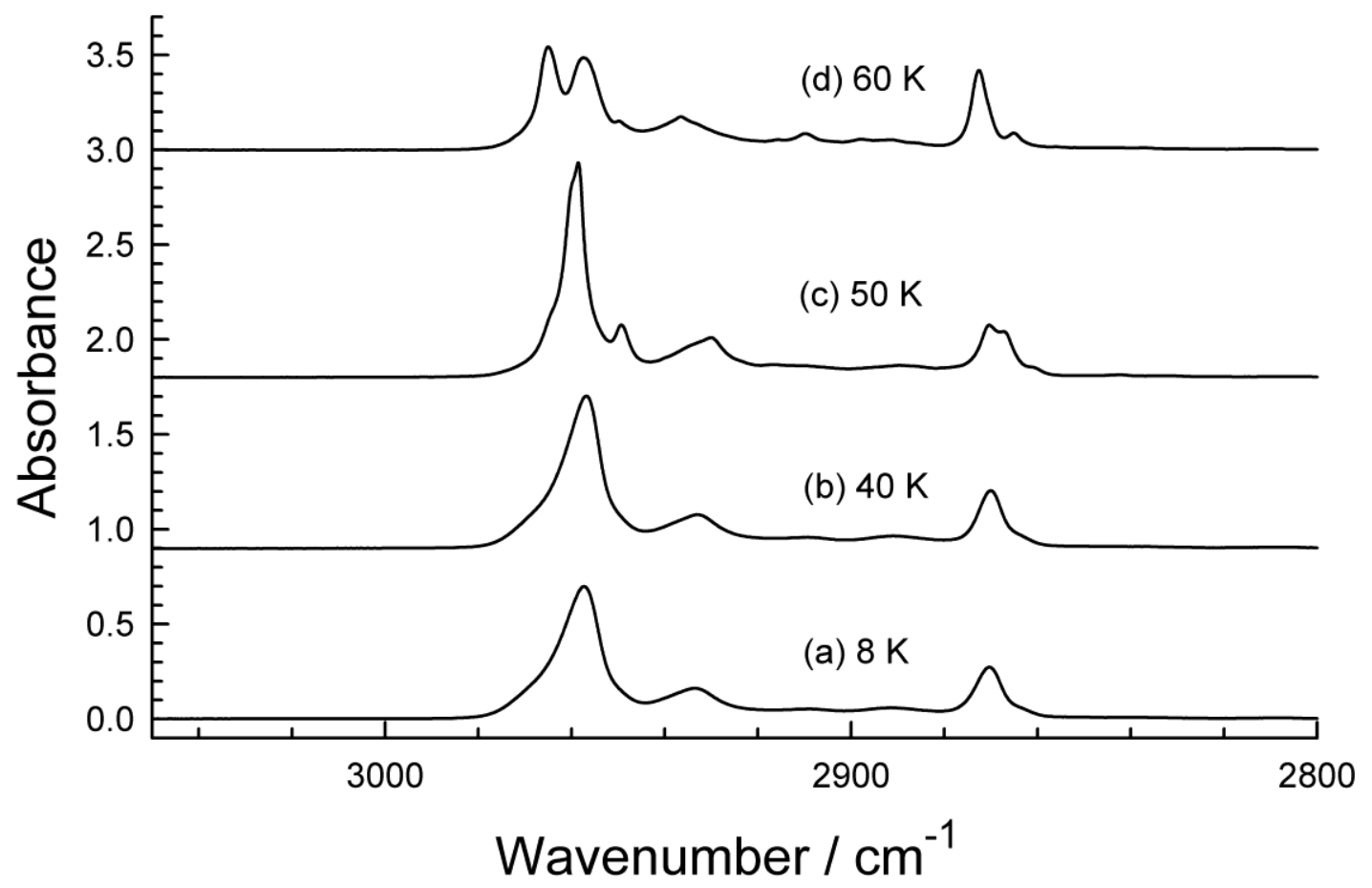

Fig. 2. Mid-IR spectra of $\mathrm{C}_{3} \mathrm{H}_{8}$ deposited at $8 \mathrm{~K}$ and warmed to the temperatures indicated. Spectra are offset for clarity. 


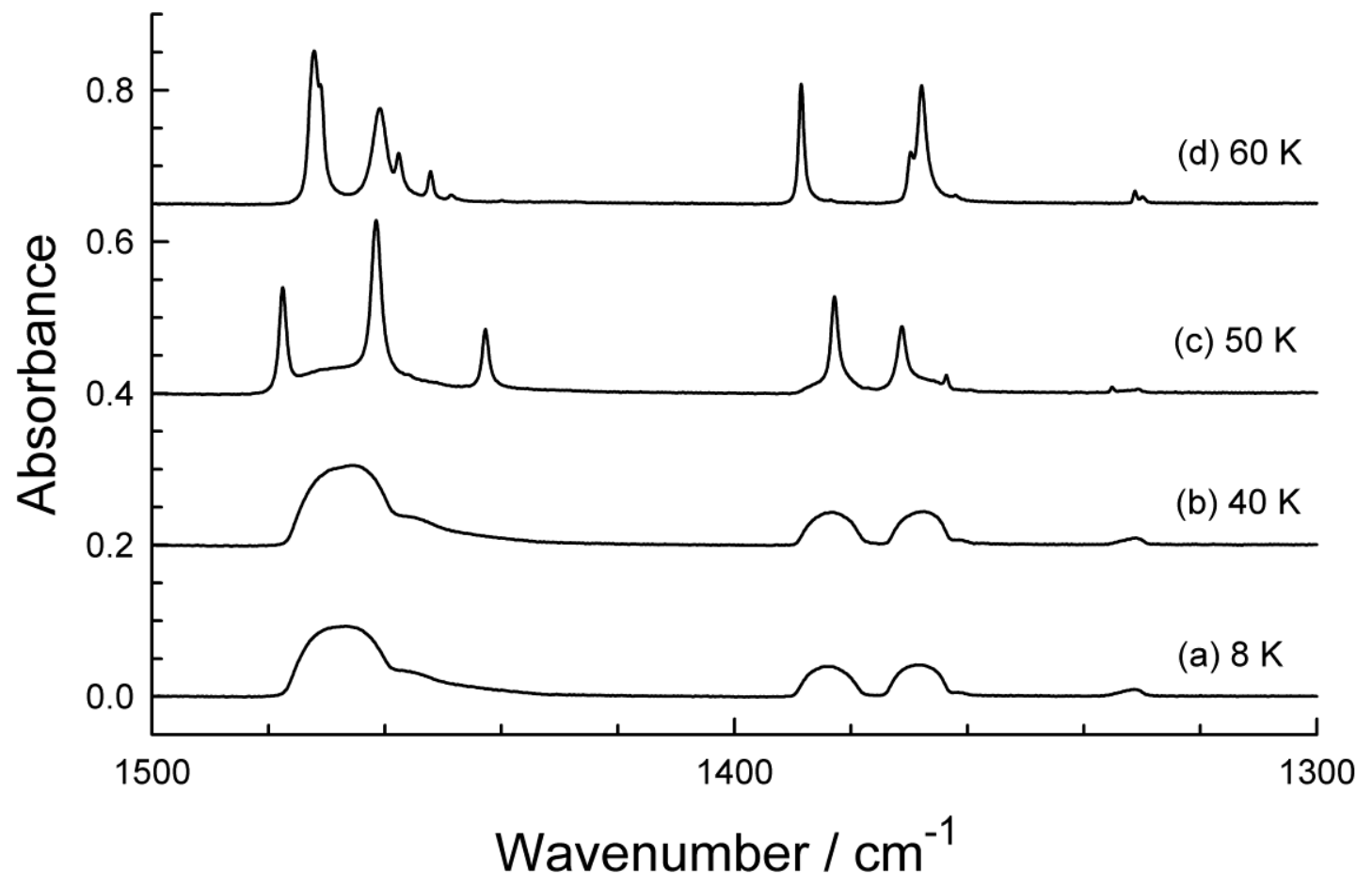

Fig. 3. Mid-IR spectra of $\mathrm{C}_{3} \mathrm{H}_{8}$ deposited at $8 \mathrm{~K}$ and warmed to the temperatures indicated. Spectra are offset for clarity. 


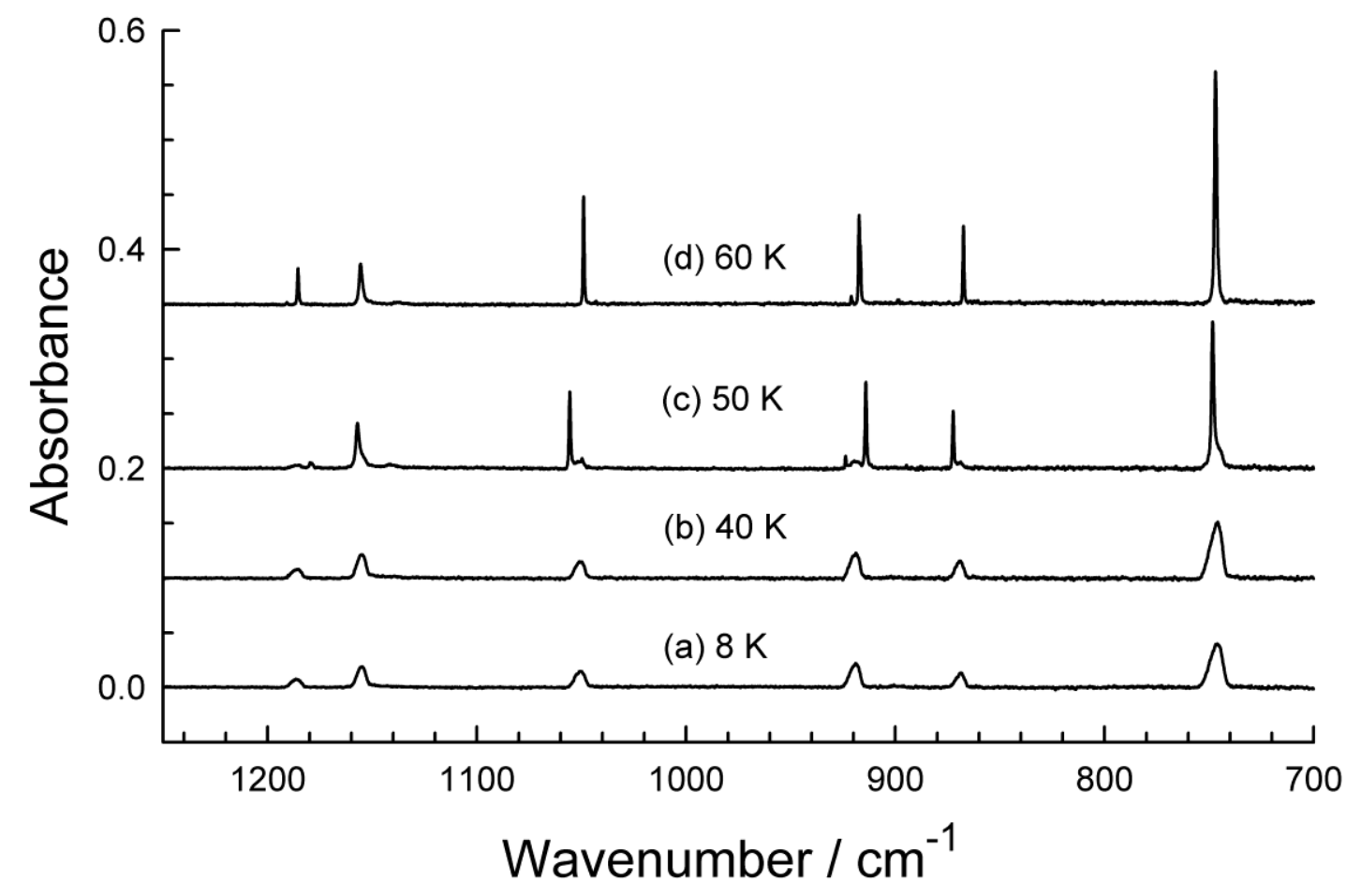

Fig. 4. Mid-IR spectra of $\mathrm{C}_{3} \mathrm{H}_{8}$ deposited at $8 \mathrm{~K}$ and warmed to the temperatures indicated. Spectra are offset for clarity.

The sharpening, splitting, and shifts of propane's IR features on warming from 40 to $50 \mathrm{~K}$ are all signs of the amorphous ice's crystallization. The additional changes seen at $60 \mathrm{~K}$ suggest that a second phase change occurred, a crystalline-crystalline transition. Repeated warming and cooling failed to reverse either change. For convenience, we refer to the crystalline ice first encountered on warming as phase I and the second crystalline ice met as phase II. Slow cooling of the phase II ice from $\sim 60 \mathrm{~K}$ and higher to the $50-60 \mathrm{~K}$ region did not reconvert it into the phase I solid.

Positions of selected spectral peaks of our propane ices are given in Tables 2 4. Also included in these tables are approximate assignments and descriptions for peaks and vibrational modes, respectively. In most cases, these descriptions are highly simplified, as can be seen from Gough et al. (1986), which should be consulted for potential energy distributions and additional references. Smaller spectral features, such as overtone and combination peaks, were seen, but not studied. 
In addition to the warming sequence from $8 \mathrm{~K}$ in Figs. 1 - 4, propane was deposited at various temperatures up to $\sim 80 \mathrm{~K}$. Deposition near $50 \mathrm{~K}$ gave the spectrum of the phase I ice, deposition at $60 \mathrm{~K}$ gave the phase II form, and deposition at $55 \mathrm{~K}$ gave a mixture of the two. The spectra of ices deposited at these particular temperatures were essentially the same as those made by depositing near $8 \mathrm{~K}$ and warming.

\section{Table 2}

Positions and intensities of selected IR features of amorphous $\mathrm{C}_{3} \mathrm{H}_{8}$ at $8 \mathrm{~K}$.

\begin{tabular}{|c|c|c|c|c|}
\hline $\begin{array}{l}\text { Approximate } \\
\text { description }^{a}\end{array}$ & $\tilde{v} / \mathrm{cm}^{-1}$ & $\alpha^{\prime} / \mathrm{cm}^{-1}$ & $\begin{array}{c}\text { Integration } \\
\text { range } / \mathrm{cm}^{-1}\end{array}$ & $\begin{array}{l}A^{\prime} / 10^{-18} \mathrm{~cm} \\
\text { molecule }\end{array}$ \\
\hline $\mathrm{CH}$ stretches & 2957 & 18000 & & \\
\hline $\mathrm{CH}$ stretches & 2870 & 6980 & $3000-2850$ & 44.6 \\
\hline $\begin{array}{l}\mathrm{CH}_{3}, \mathrm{CH}_{2} \\
\text { scissoring }\end{array}$ & 1466 & 2220 & $1500-1410$ & 4.70 \\
\hline $\begin{array}{l}\mathrm{CH}_{3} \mathrm{CH} \text { wagging } \\
\text { (in phase) }\end{array}$ & 1384 & 943 & $1393-1375$ & 0.881 \\
\hline $\begin{array}{c}\mathrm{CH}_{3} \mathrm{CH} \text { wagging } \\
\text { (out of phase) }\end{array}$ & 1368 & 954 & $1375-1355$ & 0.906 \\
\hline $\mathrm{CH}_{2} \mathrm{CH}$ wagging & 1331 & 189 & $1340-1325$ & 0.0840 \\
\hline $\mathrm{CH}_{3} / \mathrm{CH}_{2}$ rocking & 1186 & 164 & $1195-1180$ & 0.101 \\
\hline $\begin{array}{l}\mathrm{CH}_{3} \text { wagging, } \\
\text { deformation }\end{array}$ & 1155 & 436 & $1165-1140$ & 0.278 \\
\hline C-C a-stretching & 1051 & 324 & $1060-1040$ & 0.213 \\
\hline $\begin{array}{c}\mathrm{CH}_{3} \mathrm{CCH} \\
\text { deformation }\end{array}$ & 919 & 484 & $930-908$ & 0.331 \\
\hline C-C s-stretching & 869 & 319 & $880-860$ & 0.178 \\
\hline $\begin{array}{c}\mathrm{CH}_{2}, \mathrm{CH}_{3} \text { twisting, } \\
\text { rocking }\end{array}$ & 746 & 975 & $755-735$ & 0.816 \\
\hline
\end{tabular}

a Approximate descriptions are taken from Gough et al. (1987) and references therein; $\mathrm{a}=$ antisymmetric; $\mathrm{s}=$ symmetric. 


\section{Table 3}

Positions and intensities of selected IR features of metastable crystalline $\mathrm{C}_{3} \mathrm{H}_{8}$ at $50 \mathrm{~K}$.

\begin{tabular}{|c|c|c|c|c|}
\hline $\begin{array}{l}\text { Approximate } \\
\text { description }^{\mathrm{a}}\end{array}$ & $\tilde{v} / \mathrm{cm}^{-1}$ & $\alpha^{\prime} / \mathrm{cm}^{-1}$ & $\begin{array}{l}\text { Integration } \\
\text { range } / \mathrm{cm}^{-1}\end{array}$ & $\begin{array}{c}A^{\prime} / 10^{-18} \mathrm{~cm} \\
\text { molecule }^{-1}\end{array}$ \\
\hline $\mathrm{CH}$ stretches & 2958 & 20800 & & \\
\hline $\mathrm{CH}$ stretches & 2870 & 6620 & $3000-2800$ & 36.3 \\
\hline $\begin{array}{l}\mathrm{CH}_{3}, \mathrm{CH}_{2} \\
\text { scissoring }\end{array}$ & 1462 & 2900 & $1500-1400$ & 3.81 \\
\hline $\begin{array}{l}\mathrm{CH}_{3} \mathrm{CH} \text { wagging } \\
\text { (in phase) }\end{array}$ & 1383 & 1710 & $1393-1375$ & 0.662 \\
\hline $\begin{array}{l}\mathrm{CH}_{3} \mathrm{CH} \text { wagging } \\
\text { (out of phase) }\end{array}$ & 1371 & 1260 & $1375-1355$ & 0.672 \\
\hline $\mathrm{CH}_{2} \mathrm{CH}$ wagging & 1331 & 159 & $1340-1325$ & 0.054 \\
\hline $\mathrm{CH}_{3} / \mathrm{CH}_{2}$ rocking & 1185 & 113 & $1193-1180$ & 0.045 \\
\hline $\begin{array}{l}\mathrm{CH}_{3} \text { wagging, } \\
\text { deformation }\end{array}$ & 1157 & 853 & $1165-1145$ & 0.238 \\
\hline C-C a-stretching & 1056 & 713 & $1060-1045$ & 0.203 \\
\hline $\begin{array}{l}\mathrm{CH}_{3} \mathrm{CCH} \\
\text { deformation }\end{array}$ & 914 & 812 & $925-910$ & 0.306 \\
\hline C-C s-stretching & 872 & 576 & $875-860$ & 0.165 \\
\hline $\begin{array}{l}\mathrm{CH}_{2}, \mathrm{CH}_{3} \text { twisting, } \\
\text { rocking }\end{array}$ & 748 & 1760 & $760-735$ & 0.786 \\
\hline
\end{tabular}

a Approximate descriptions are taken from Gough et al. (1987) and references therein; $\mathrm{a}=$ antisymmetric; $\mathrm{s}=$ symmetric. 


\section{Table 4}

Positions and intensities of selected IR features of stable crystalline $\mathrm{C}_{3} \mathrm{H}_{8}$ at $65 \mathrm{~K}$.

\begin{tabular}{|c|c|c|c|c|}
\hline $\begin{array}{l}\text { Approximate } \\
\text { description }^{\mathrm{a}}\end{array}$ & $\tilde{v} / \mathrm{cm}^{-1}$ & $\alpha^{\prime} / \mathrm{cm}^{-1}$ & $\begin{array}{c}\text { Integration } \\
\text { range } / \mathrm{cm}^{-1}\end{array}$ & $\begin{array}{l}A^{\prime} / 10^{-18} \mathrm{~cm} \\
\text { molecule }{ }^{-1}\end{array}$ \\
\hline $\mathrm{CH}$ stretches & 2957 & 6020 & & \\
\hline $\mathrm{CH}$ ctrotchec & ل & 1170 & $3000-2800$ & 18.7 \\
\hline CH stretches & $28 / 2$ & $44 / 0$ & & \\
\hline $\begin{array}{l}\mathrm{CH}_{3}, \mathrm{CH}_{2} \\
\text { scissoring }\end{array}$ & 1472 & 2860 & $1500-1400$ & 1.81 \\
\hline $\begin{array}{c}\mathrm{CH}_{3} \mathrm{CH} \text { wagging } \\
\text { (in phase) }\end{array}$ & 1388 & 2180 & $1393-1375$ & 0.315 \\
\hline $\begin{array}{c}\mathrm{CH}_{3} \mathrm{CH} \text { wagging } \\
\text { (out of phase) }\end{array}$ & 1368 & 1710 & $1375-1355$ & 0.474 \\
\hline $\mathrm{CH}_{2} \mathrm{CH}$ wagging & 1331 & 164 & $1340-1325$ & 0.0163 \\
\hline $\mathrm{CH}_{3} / \mathrm{CH}_{2}$ rocking & 1185 & 542 & $1190-1180$ & 0.0489 \\
\hline $\begin{array}{c}\mathrm{CH}_{3} \text { wagging, } \\
\text { deformation }\end{array}$ & 1156 & 522 & $1165-1145$ & 0.107 \\
\hline C-C a-stretching & 1049 & 989 & $1052-1046$ & 0.0851 \\
\hline $\begin{array}{l}\mathrm{CH}_{3} \mathrm{CCH} \\
\text { deformation }\end{array}$ & 917 & 843 & $920-914$ & 0.0907 \\
\hline C-C s-stretching & 867 & 1040 & $870-865$ & 0.0765 \\
\hline $\begin{array}{l}\mathrm{CH}_{2}, \mathrm{CH}_{3} \text { twisting, } \\
\text { rocking }\end{array}$ & 746 & 3510 & $752-742$ & 0.534 \\
\hline
\end{tabular}

a Approximate descriptions are taken from Gough et al. (1987) and references therein; $\mathrm{a}=$ antisymmetric; $\mathrm{s}=$ symmetric. 
We also found that for propane ices with thicknesses of a few micrometers, it was possible to warm them above propane's melting point of $\sim 85 \mathrm{~K}$ and to record the IR spectrum of the resulting liquid before its complete evaporation, which typically was only a few minutes. Liquid-phase spectra are not shown here, but resembled those of amorphous propane, as expected. Perhaps more significant is that on cooling liquid propane, the ice that formed was always in the crystalline phase-II form. Repeated warmings of such crystalline ices gave a melting point between 85.5 and $85.9 \mathrm{~K}$, in agreement with the literature (Pavese and Besley, 1981). In a few cases, supercooling of liquid propane was observed, in one case as low as $78 \mathrm{~K}$. The tendency of both propane and propylene to undergo supercooling has been known for about a century, and perhaps longer (Maass and Wright, 1921).

\subsection{Propane - infrared intensities}

Before continuing we should mention previous IR studies of solid propane. An older paper of Snyder and Schachtschenider (1963) listed peak positions at 1500 - 700 $\mathrm{cm}^{-1}$ for a propane ice at $77 \mathrm{~K}$, which are close to those of our phase II solid, although the authors describe their sample as "a very viscous liquid" and the relative intensities of their spectrum's peaks do not match ours. A publication by Goodman et al. (1983) included a spectrum and a list of peak positions for crystalline propane at $77 \mathrm{~K}$. Their spectrum covered only the 1400 to $700 \mathrm{~cm}^{-1}$ region, but their peaks' positions, spacings, and relative intensities suggest that the authors made the phase II form of crystalline propane. Coustenis et al. (1999) showed an IR spectrum of solid propane at $80 \mathrm{~K}$, which also appears to correspond to our phase II ice. Much more recently, Ghosh et al. (2018) published IR spectra of solid propane similar to our own, but their spectra were collected in a reflection mode preventing a direct comparison of peak positions and intensities to our work (e.g., Maeda and Schatz, 1961). Nevertheless, it is clear that those authors found the same three solid forms we observed and at comparable temperatures. We will return to their paper in our Discussion section.

Our point here is simply to emphasize that none of the earlier papers provided quantitative measures of IR spectral intensities for solid propane, an important motivation for our investigation. In response, we prepared ice samples of various thicknesses for amorphous and crystalline propane and recorded their transmission IR spectra. The usual Beer's Law graphs gave values of the apparent absorption coefficient $(\alpha)$ and apparent band strengths $(A)$ for selected peaks and regions, all of which are summarized in Tables 2 - 4.

\subsection{Propylene - infrared spectra and infrared intensities}

Our work with propylene followed the pattern just described for propane. In Fig. 5, mid-IR survey spectra for propylene are shown for four temperatures, with expansions in Figs. 6 - 8. Going from the bottom to the top, traces (a) and (b) are from 
an amorphous propylene sample made at $9 \mathrm{~K}$ and then warmed to $60 \mathrm{~K}$. Trace (c) shows sharpening, shifting, and splitting of peaks on crystallization of the ice by $70 \mathrm{~K}$, followed by a second crystallization for spectrum (d) at $80 \mathrm{~K}$. Each crystallization was complete at these temperatures in about 1 minute, but could be accomplished by holding the sample at lower temperatures for longer times. Such changes, as with propane, were never reversed on recooling the ice. Again as with propane, it was possible to warm propylene to its melting point near $87 \mathrm{~K}$ and to record IR spectra of the resulting liquid as it evaporated, which occurred in only a few minutes. Such spectra resembled those in trace (a) of Figs. $\mathbf{5}$ - $\mathbf{8}$, as expected. No attempt was made to narrow down the temperature ranges for crystallizations and other changes, nor to investigate the kinetics of such processes.

The behavior of amorphous propylene on warming differed somewhat from that of amorphous propane. The warming of propylene from $\sim 9 \mathrm{~K}$ typically gave a mixture of two crystalline forms near $70 \mathrm{~K}$, which evolved into a single crystalline form by $80 \mathrm{~K}$. This can be seen upon close inspection of Figs. $\mathbf{5}-\mathbf{8}$, but is much easier to see in the expansion of Fig. 9. Trace (a) is a typical result, obtained on warming propylene from 8 to $70 \mathrm{~K}$. Further warming gave spectrum (b) at $80 \mathrm{~K}$, which could be subtracted from (a) to give the difference spectrum (c). That this represents a single crystalline form is supported by trace (d), obtained on deposition of propylene at $75 \mathrm{~K}$ to give a crystalline phase-l ice spectrum. In short, the warming of amorphous propylene often gave a mixture of the two crystalline phases. We did not investigate all of the factors involved, but we did determine that deposition at $\sim 70 \mathrm{~K}$ consistently gave the phase I ice and deposition at $\sim 80 \mathrm{~K}$ always gave the phase II ice, and these were the conditions used to prepare samples for intensity measurements.

Tables $\mathbf{5}$ - $\mathbf{7}$ give peak positions for our three forms of solid propylene, along with assignments and descriptions for IR peaks and vibrational modes, respectively. As with the case of propane, in most instances these descriptions are highly simplified. See Silvi et al. (1973) for more information, such as potential energy distributions and additional references. Infrared intensities for solid propylene, both absorption coefficients and band strengths, again were determined from the appropriate Beer's Law plots. See Tables $\mathbf{5}-\mathbf{7}$ for results. 


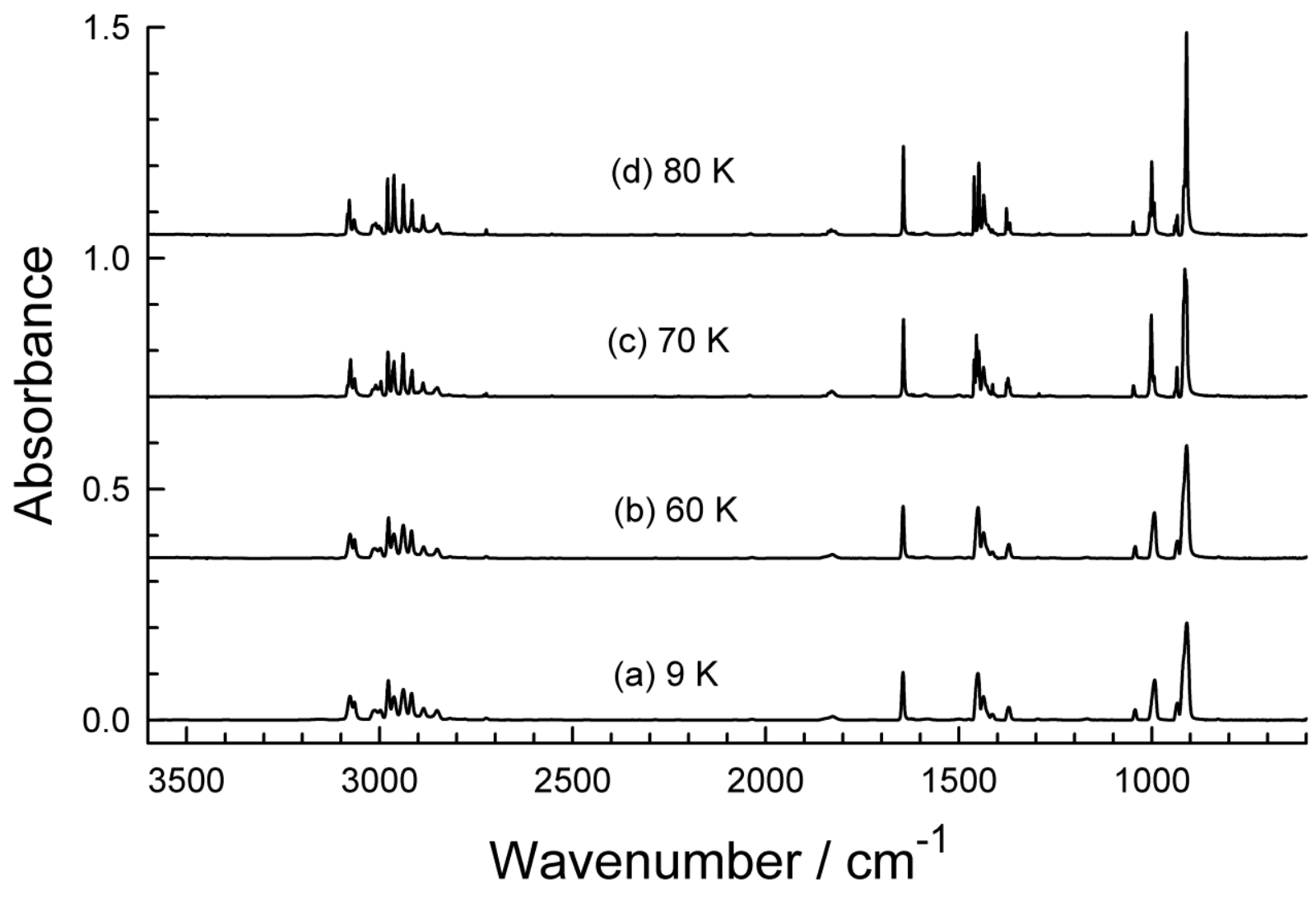

Fig. 5. Mid-IR survey spectra of $\mathrm{C}_{3} \mathrm{H}_{6}$ deposited at $9 \mathrm{~K}$ and warmed to the temperatures indicated. Spectra are offset for clarity. 


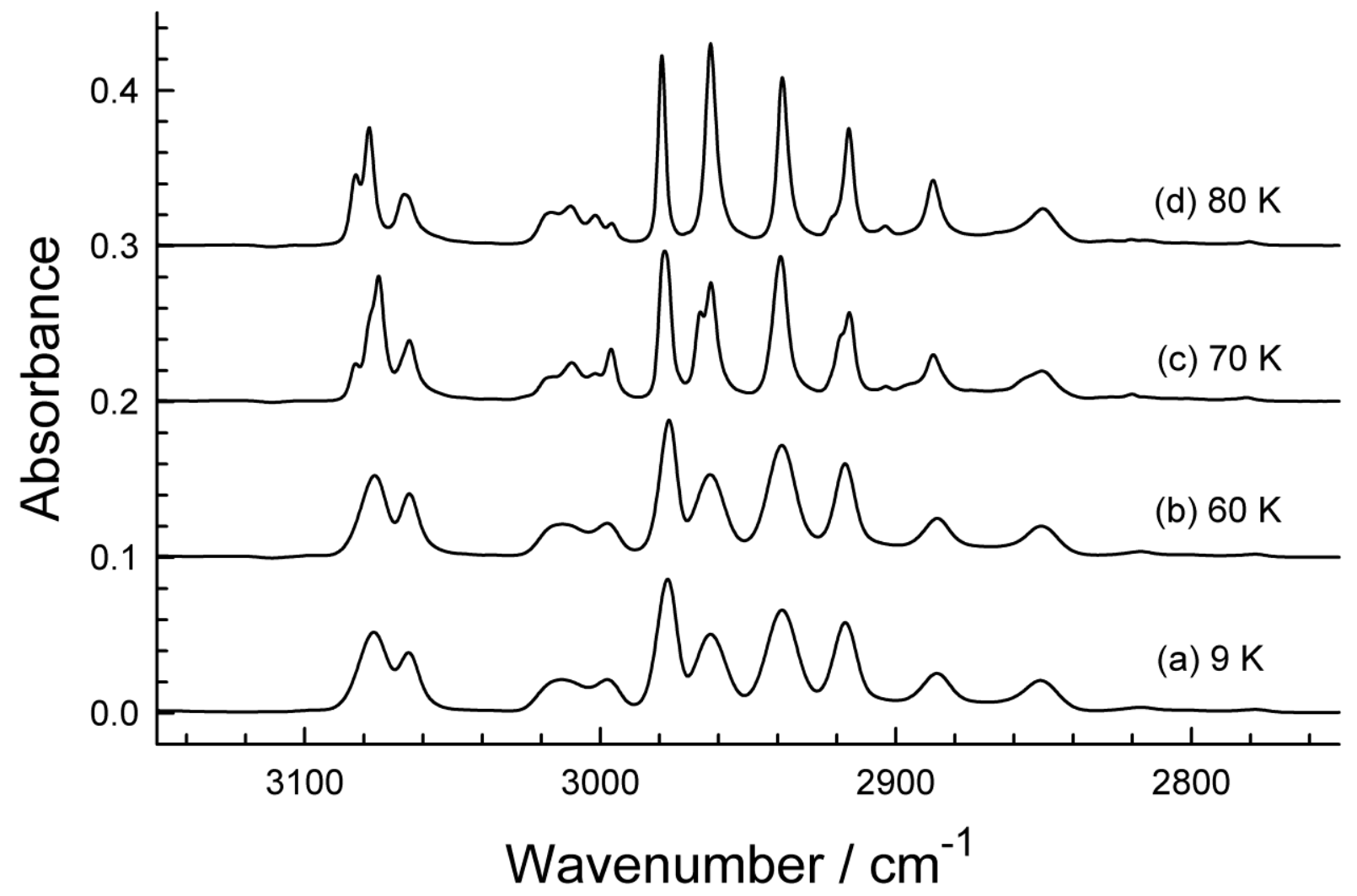

Fig. 6. Mid-IR spectra of $\mathrm{C}_{3} \mathrm{H}_{6}$ deposited at $9 \mathrm{~K}$ and warmed to the temperatures indicated. Spectra are offset for clarity. 


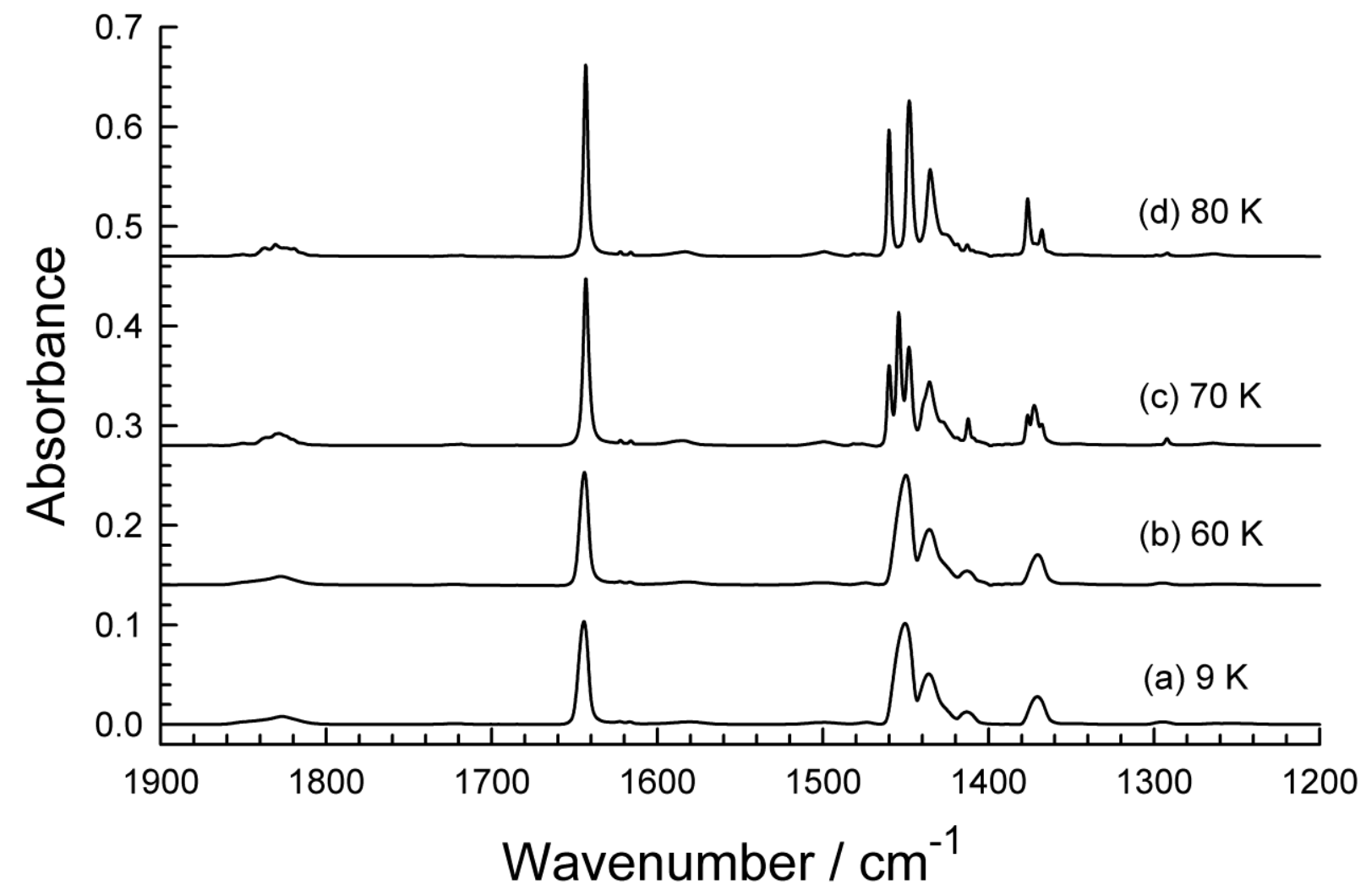

Fig. 7. Mid-IR spectra of $\mathrm{C}_{3} \mathrm{H}_{6}$ deposited at $9 \mathrm{~K}$ and warmed to the temperatures indicated. Spectra are offset for clarity. 


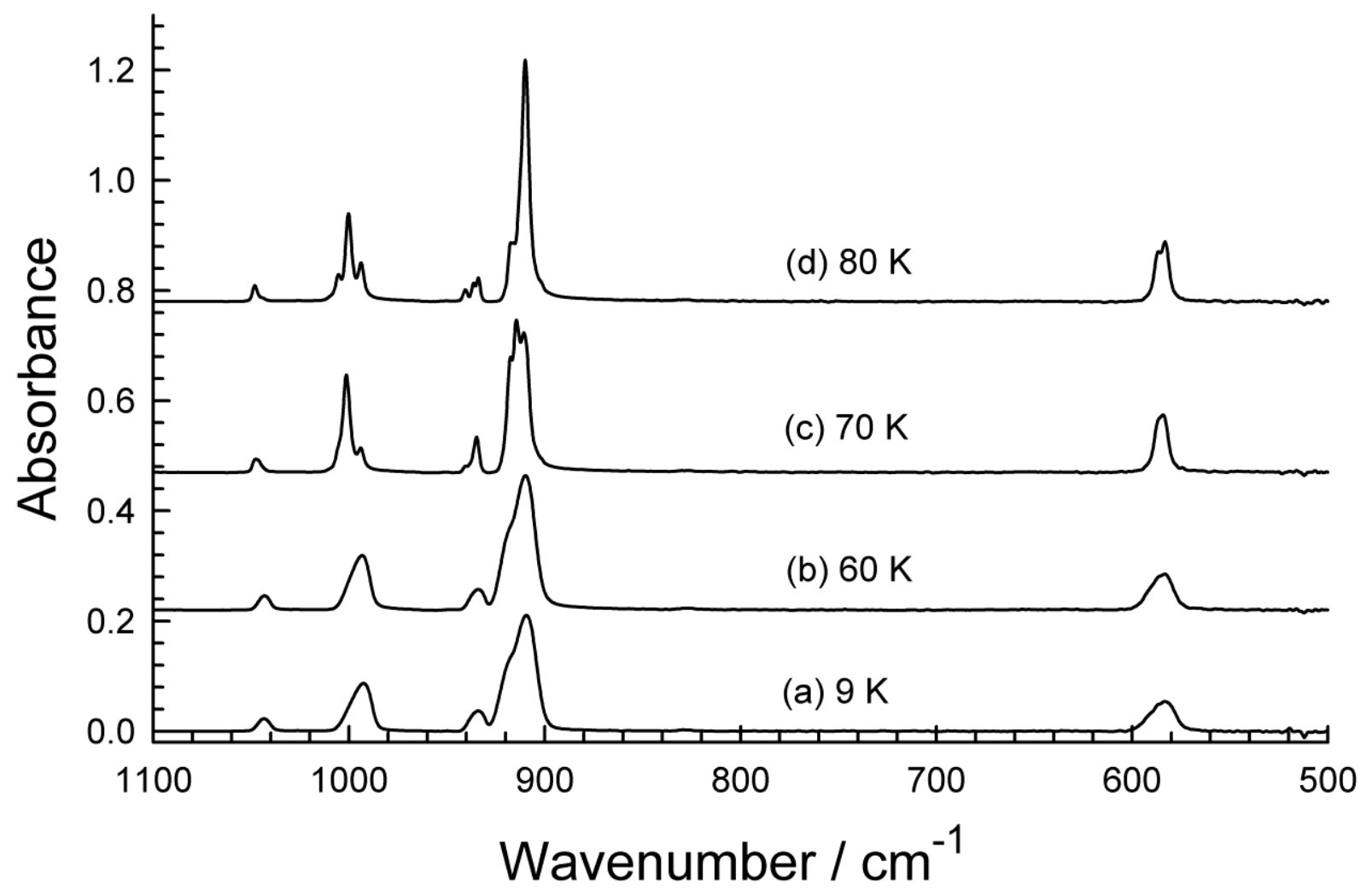

Fig. 8. Mid-IR spectra of $\mathrm{C}_{3} \mathrm{H}_{6}$ deposited at $9 \mathrm{~K}$ and warmed to the temperatures indicated. Spectra are offset for clarity. 


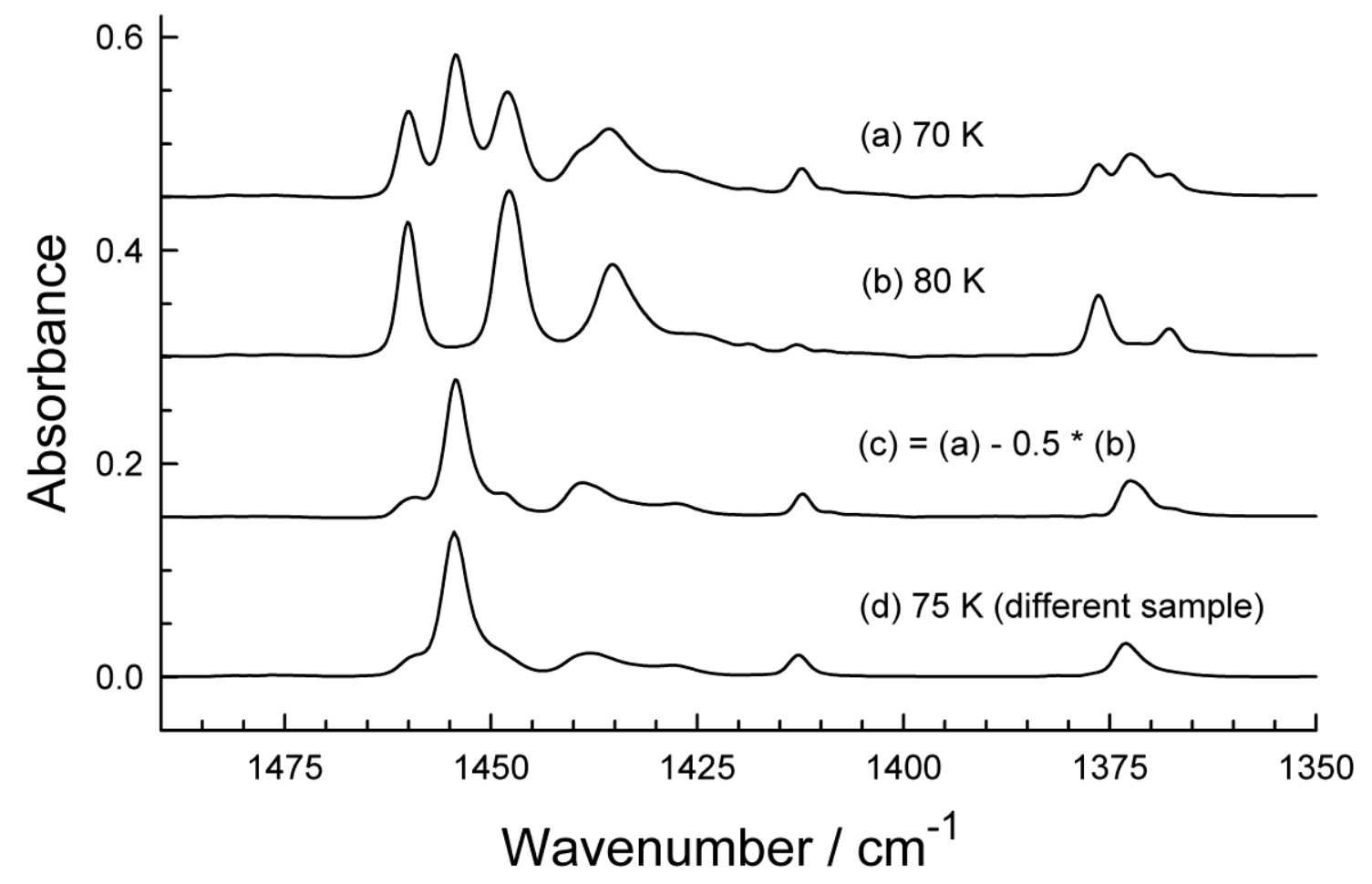

Fig. 9. Mid-IR spectra of $\mathrm{C}_{3} \mathrm{H}_{6}$ deposited at $9 \mathrm{~K}$ and warmed to (a) $70 \mathrm{~K}$ and then to (b) $80 \mathrm{~K}$. Trace (c) is a difference spectrum and trace (d) is for a propylene ice made at $75 \mathrm{~K}$. Spectra are offset for clarity. 


\section{Table 5}

Positions and intensities of selected IR features of amorphous $\mathrm{C}_{3} \mathrm{H}_{6}$ at $8 \mathrm{~K}$.

\begin{tabular}{ccccc}
\hline $\begin{array}{c}\text { Approximate } \\
\text { description }\end{array}$ & $\tilde{v} / \mathrm{cm}^{-1}$ & $\alpha^{\prime} / \mathrm{cm}^{-1}$ & $\begin{array}{c}\text { Integration } \\
\text { range } / \mathrm{cm}^{-1}\end{array}$ & $\begin{array}{c}A^{\prime} / 10^{-18} \mathrm{~cm} \\
\text { molecule }^{-1}\end{array}$ \\
\hline $\mathrm{CH}_{2}$ a-stretches & 3077 & 1220 & $3120-3040$ & 2.44 \\
$\mathrm{CH}_{2}$ s-stretches & 2977 & 2070 & & \\
$\mathrm{CH}_{3}$ a-stretches & 2938 & 1600 & $3040-2750$ & 10.7 \\
$\mathrm{CH}_{3}$ s-stretches & 2917 & 1250 & & \\
$\mathrm{C}=\mathrm{C}$ stretch & 1644 & 2300 & $1660-1630$ & 1.69 \\
$\mathrm{CH}_{3}$ a-bending & 1450 & 2210 & $1466-1400$ & 4.44 \\
$\mathrm{CH}_{3}$ s-bending & 1370 & 587 & $1385-1355$ & 0.657 \\
$\mathrm{CH}_{3}$ wagging & 1043 & 457 & $1055-1030$ & 0.385 \\
$\begin{array}{c}\mathrm{CH} \text { bending } \\
\mathrm{CH}_{2} \text { bending / C-C }\end{array}$ & 993 & 1798 & $1015-975$ & 2.40 \\
stretching & 909 & 4250 & $950-880$ & 8.33 \\
$\mathrm{C}-\mathrm{CH}_{2}$ twisting & 585 & 871 & $610-565$ & 1.35 \\
\hline
\end{tabular}

a Approximate descriptions are taken from Silvi et al. (1973) and references therein; $\mathrm{a}=$ antisymmetric; $\mathrm{s}=$ symmetric. 


\section{Table 6}

Positions and intensities of selected IR features of metastable crystalline $\mathrm{C}_{3} \mathrm{H}_{6}$ at $65 \mathrm{~K}$.

\begin{tabular}{ccccc}
\hline $\begin{array}{c}\text { Approximate } \\
\text { description }\end{array}$ & $\tilde{v} / \mathrm{cm}^{-1}$ & $\alpha^{\prime} / \mathrm{cm}^{-1}$ & $\begin{array}{c}\text { Integration } \\
\text { range } / \mathrm{cm}^{-1}\end{array}$ & $\begin{array}{c}A^{\prime} / 10^{-18} \mathrm{~cm} \\
\text { molecule }^{-1}\end{array}$ \\
\hline $\mathrm{CH}_{2}$ a-stretches & 3075 & 4580 & $3110-3040$ & 2.42 \\
$\mathrm{CH}_{2}$ s-stretches & 2977 & 4860 & & \\
$\mathrm{CH}_{3}$ a-stretches & 2940 & 3270 & $3040-2750$ & 8.12 \\
$\mathrm{CH}_{3}$ s-stretches & 2919 & 1790 & & \\
$\mathrm{C}=\mathrm{C}$ stretch & 1641 & 3220 & $1660-1625$ & 1.91 \\
$\mathrm{CH}_{3}$ a-bending & 1454 & 9030 & $1466-1400$ & 4.78 \\
$\mathrm{CH}_{3}$ s-bending & 1371 & 2040 & $1385-1355$ & 0.747 \\
$\mathrm{CH}$ 3 wagging & 1046 & 996 & $1055-1030$ & 0.366 \\
$\mathrm{CH}_{\text {bending }}$ & 1002 & 6640 & $1015-975$ & 2.70 \\
$\mathrm{CH}_{2}$ bending / C-C & 914 & 13600 & $950-880$ & 7.80 \\
stretching & 585 & 2550 & $610-565$ & 1.57 \\
$\mathrm{C}-\mathrm{CH}{ }_{2}$ twisting & & & & \\
\hline
\end{tabular}

a Approximate descriptions are taken from Silvi et al. (1973) and references therein; $\mathrm{a}=$ antisymmetric; $\mathrm{s}=$ symmetric. 
Table 7

Positions and intensities of selected IR features of stable crystalline $\mathrm{C}_{3} \mathrm{H}_{6}$ at $80 \mathrm{~K}$.

\begin{tabular}{ccccc}
\hline $\begin{array}{c}\text { Approximate } \\
\text { description }\end{array}$ & $\tilde{v} / \mathrm{cm}^{-1}$ & $\alpha^{\prime} / \mathrm{cm}^{-1}$ & $\begin{array}{c}\text { Integration } \\
\text { range } / \mathrm{cm}^{-1}\end{array}$ & $\begin{array}{c}A^{\prime} / 10^{-18} \mathrm{~cm} \\
\text { molecule }^{-1}\end{array}$ \\
\hline $\mathrm{CH}_{2}$ a-stretches & 3078 & 1090 & $3100-3040$ & 1.04 \\
$\mathrm{CH}_{2}$ s-stretches & 2979 & 2990 & & \\
$\mathrm{CH}_{3}$ a-stretches & 2939 & 3750 & $3040-2750$ & 8.43 \\
$\mathrm{CH}_{3}$ s-stretches & 2916 & 3100 & & \\
$\mathrm{C}=\mathrm{C}$ stretch & 1643 & 8750 & $1660-1625$ & 2.33 \\
$\mathrm{CH}_{3}$ a-bending & 1448 & 6050 & $1466-1400$ & 5.26 \\
$\mathrm{CH}_{3}$ s-bending & 1368 & 1310 & $1385-1355$ & 0.589 \\
$\mathrm{CH}_{3}$ wagging & 1048 & 1330 & $1055-1035$ & 0.366 \\
$\begin{array}{c}\mathrm{CH} \text { bending } \\
\mathrm{CH}_{2} \text { bending / C-C }\end{array}$ & 1000 & 5410 & $1015-975$ & 3.14 \\
$\begin{array}{c}\text { stretching } \\
\mathrm{C}-\mathrm{CH}_{2} \text { twisting }\end{array}$ & 909 & 10200 & $950-880$ & 8.27 \\
\hline
\end{tabular}

a Approximate descriptions are taken from Silvi et al. (1973) and references therein; $\mathrm{a}=$ antisymmetric; $\mathrm{s}=$ symmetric. 


\subsection{Propyne - infrared spectra and infrared intensities}

Our propyne work followed the pattern already described for propane and propylene, but proved to be somewhat simpler as only one crystalline phase was found. In Figs. 10 - 13, mid-IR survey spectra for propyne are shown for three temperatures. Going from the bottom to the top, traces (a) and (b) are from an amorphous propyne sample made at $8 \mathrm{~K}$ and then warmed to $60 \mathrm{~K}$. Trace (c), for $70 \mathrm{~K}$, shows a hint of change, which is complete in (d) by $80 \mathrm{~K}$ with peaks sharpening, shifting, and splitting on crystallization of the ice, changes that were never seen to reverse on recooling the sample. Tables $\mathbf{8}$ and $\mathbf{9}$ give peak positions for our two forms of solid propyne, along with assignments and descriptions for IR peaks and vibrational modes, respectively. As with propane and propylene, in most instances these descriptions are highly simplified. Peak assignments are from the gas-phase studies of Crawford (1940) and Whitmer (1974), which should be consulted for potential energy distributions and references to earlier work. Infrared intensities for solid propyne, both absorption coefficients and band strengths, again were determined from the appropriate Beer's Law plots. See Tables 8 and 9 for results. Finally, our amorphous-propyne spectra showed small peaks for contamination by $\sim 0.1 \% \mathrm{CO}_{2}\left(2338 \mathrm{~cm}^{-1}\right)$ and $\sim 1 \%$ allene $\left(1948 \mathrm{~cm}^{-1}\right)$. Our estimate for the abundance of propyne's isomer allene (1,2-propadiene) is expected to decrease after a more-precise determination of allene's IR band strengths, which is work in progress. No work was done above about $90 \mathrm{~K}$ due to propyne's sublimation in our vacuum system.

\subsection{Optical constants}

We also have calculated IR optical constants $n$ and $k$ for the amorphous and crystalline forms of propane, propylene, and propyne. See Fig. 14 for the stable crystalline form of propane, and see the Supplementary Information for all results. Electronic versions of these optical constants are posted on our group's website (https://science.gsfc.nasa.gov/691/cosmicice/constants.html). From these numbers it is possible to calculate, among other things, IR transmission spectra for ices of various thicknesses, as well as reflection spectra. See Swanpoel (1983) for a simple method for calculating spectra from optical constants. For a method to calculate IR reflection spectra from $n$ and $k$ see Tomlin (1968). 


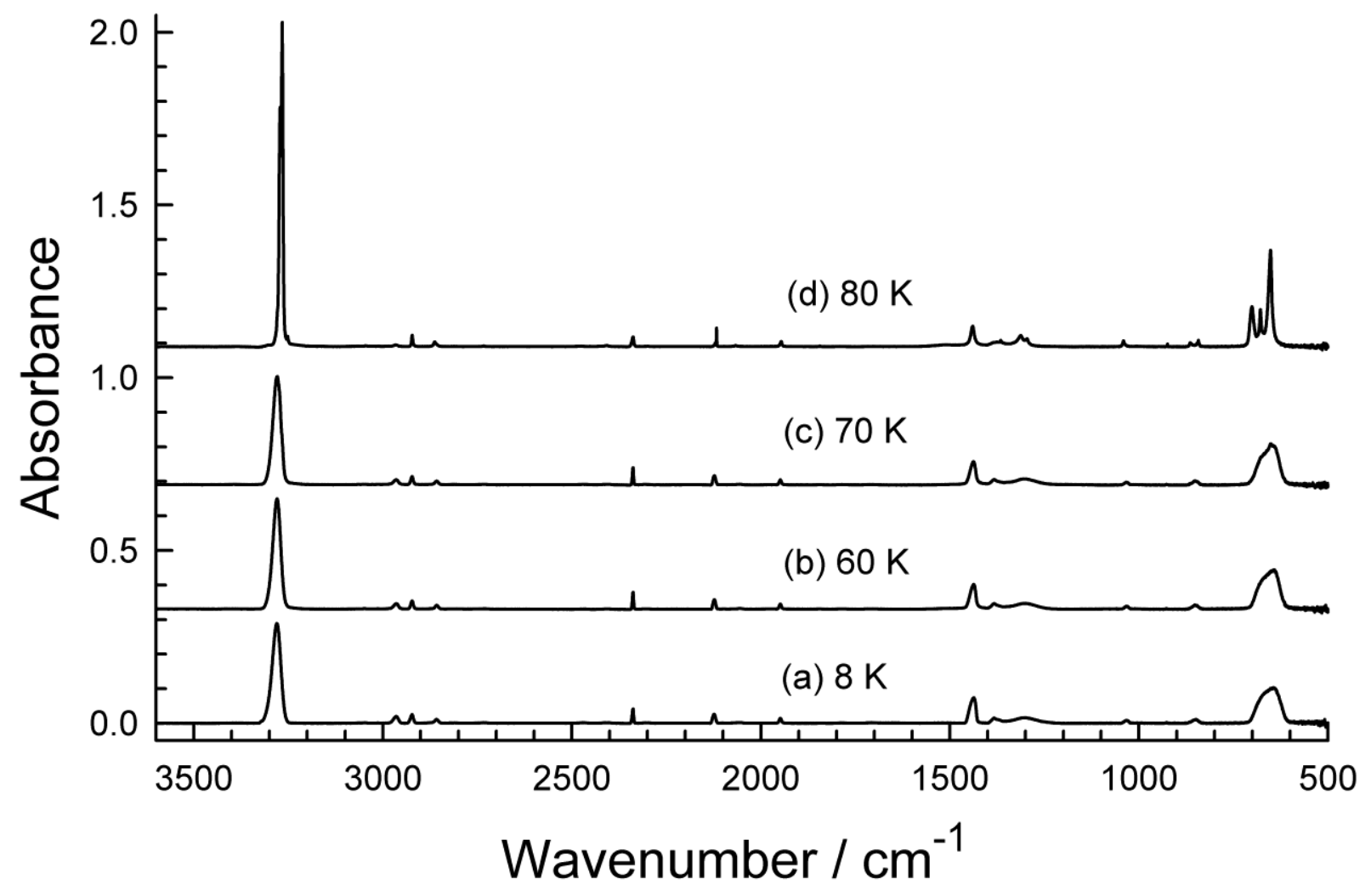

Fig. 10. Mid-IR survey spectra of $\mathrm{C}_{3} \mathrm{H}_{4}$ deposited at $8 \mathrm{~K}$ and warmed to the temperatures indicated. Spectra are offset for clarity. 


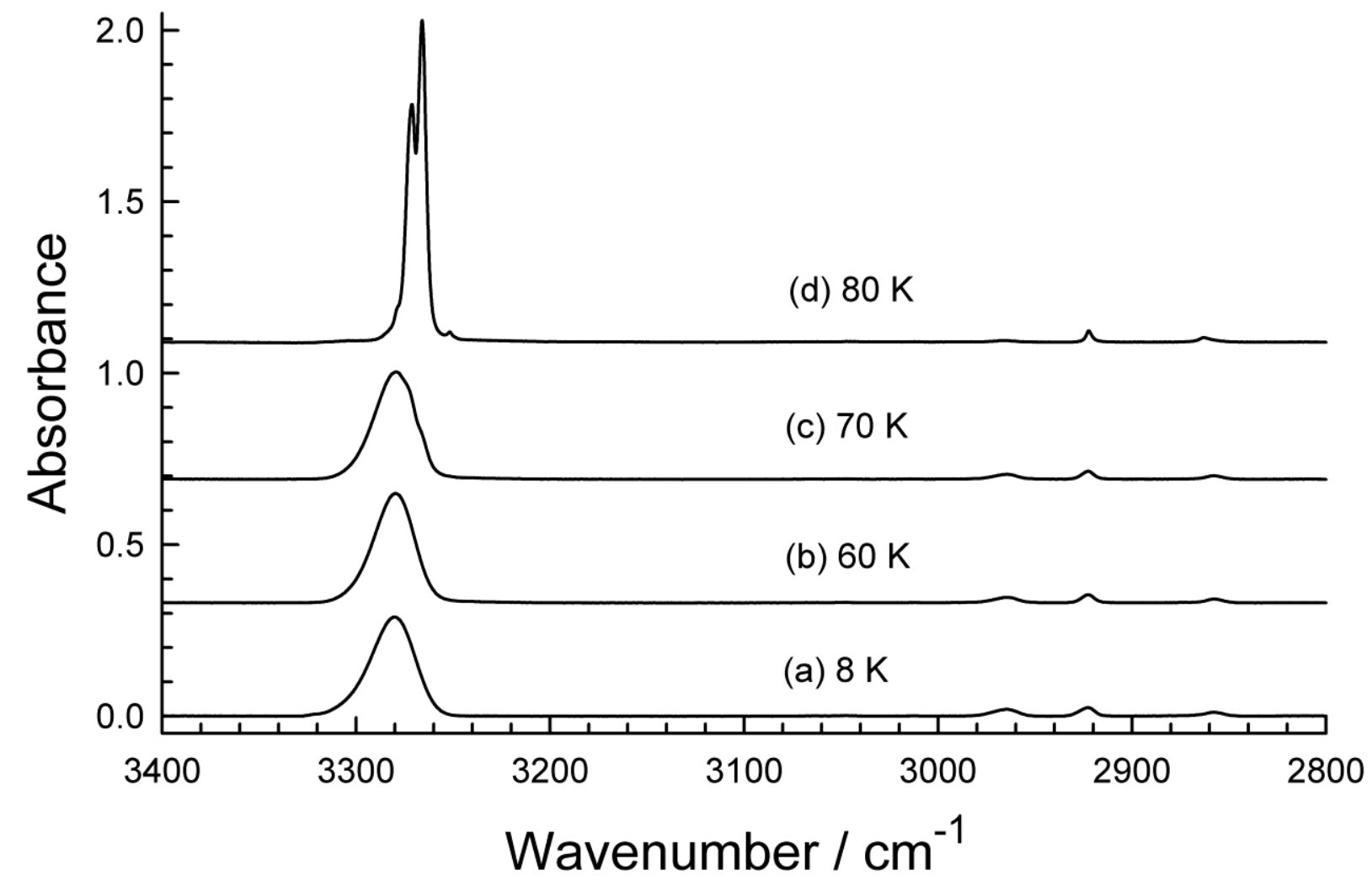

Fig. 11. Mid-IR spectra of $\mathrm{C}_{3} \mathrm{H}_{4}$ deposited at $8 \mathrm{~K}$ and warmed to the temperatures indicated. Spectra are offset for clarity. 


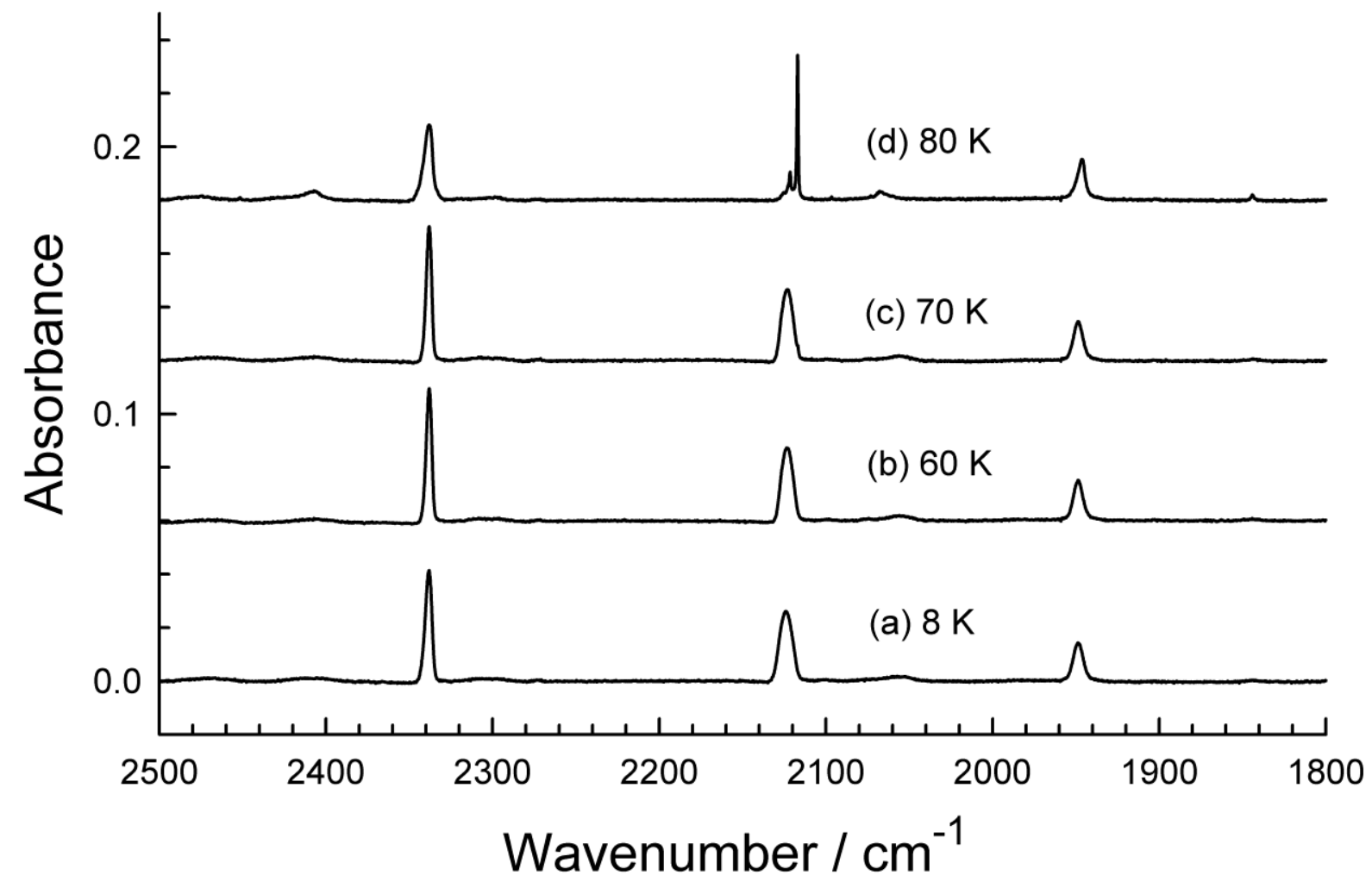

Fig. 12. Mid-IR spectra of $\mathrm{C}_{3} \mathrm{H}_{4}$ deposited at $8 \mathrm{~K}$ and warmed to the temperatures indicated. Spectra are offset for clarity. 


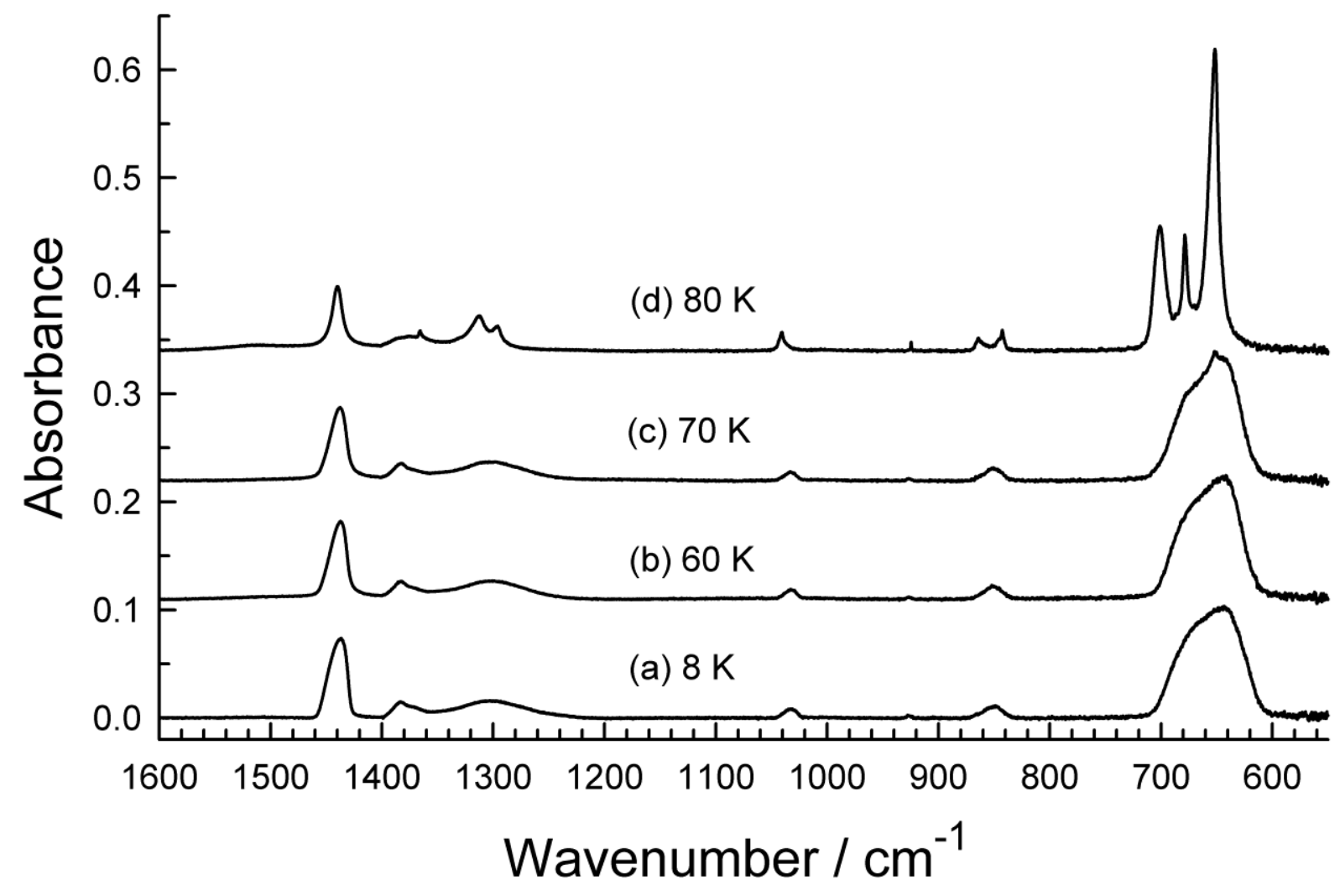

Fig. 13. Mid-IR spectra of $\mathrm{C}_{3} \mathrm{H}_{4}$ deposited at $8 \mathrm{~K}$ and warmed to the temperatures indicated. Spectra are offset for clarity. 


\section{Table 8}

Positions and intensities of selected IR features of amorphous $\mathrm{C}_{3} \mathrm{H}_{4}$ at $8 \mathrm{~K}$.

\begin{tabular}{ccccc}
\hline $\begin{array}{c}\text { Approximate } \\
\text { description }\end{array}$ & $\tilde{v} / \mathrm{cm}^{-1}$ & $\alpha^{\prime} / \mathrm{cm}^{-1}$ & $\begin{array}{c}\text { Integration } \\
\text { range } / \mathrm{cm}^{-1}\end{array}$ & $\begin{array}{c}A^{\prime} / 10^{-18} \mathrm{~cm} \\
\text { molecule }^{-1}\end{array}$ \\
\hline $\mathrm{H}-\mathrm{C} \equiv$ stretches & 3280 & 6430 & $3333-3233$ & 17.7 \\
$\mathrm{C} \equiv \mathrm{C}$ stretch & 2124 & 540 & $2136-2112$ & 0.469 \\
$\mathrm{C}-\mathrm{H}$ bending & 1437 & 1570 & $1462-1414$ & 2.87 \\
$\mathrm{H}-\mathrm{C} \equiv \mathrm{C}$ bending & 645 & 2190 & $720-590$ & 13.3 \\
\hline
\end{tabular}

a Approximate descriptions are from Crawford (1940) and Whitmer (1974).

\section{Table 9}

Positions and intensities of selected IR features of crystalline $\mathrm{C}_{3} \mathrm{H}_{4}$ at $80 \mathrm{~K}$.

\begin{tabular}{ccccc}
\hline $\begin{array}{c}\text { Approximate } \\
\text { description }\end{array}$ & $\tilde{v} / \mathrm{cm}^{-1}$ & $\alpha^{\prime} / \mathrm{cm}^{-1}$ & $\begin{array}{c}\text { Integration } \\
\text { range } / \mathrm{cm}^{-1}\end{array}$ & $\begin{array}{c}A^{\prime} / 10^{-18} \mathrm{~cm} \\
\text { molecule }^{-1}\end{array}$ \\
\hline $\mathrm{H}-\mathrm{C} \equiv$ stretches & 3266 & 54100 & $3290-3240$ & 29.1 \\
$\mathrm{C} \equiv \mathrm{C}$ stretch & 2177 & 3820 & $2119-2114$ & 0.197 \\
$\mathrm{C}-\mathrm{H}$ bending & 1441 & 1970 & $1460-1410$ & 1.10 \\
$\mathrm{H}-\mathrm{C} \equiv \mathrm{C}$ bending & 700 & 8220 & $720-660$ & 9.84 \\
$\mathrm{H}-\mathrm{C} \equiv \mathrm{C}$ bending & 678 & 9270 & & \\
\hline
\end{tabular}

a Approximate descriptions are from Crawford (1940) and Whitmer (1974). 

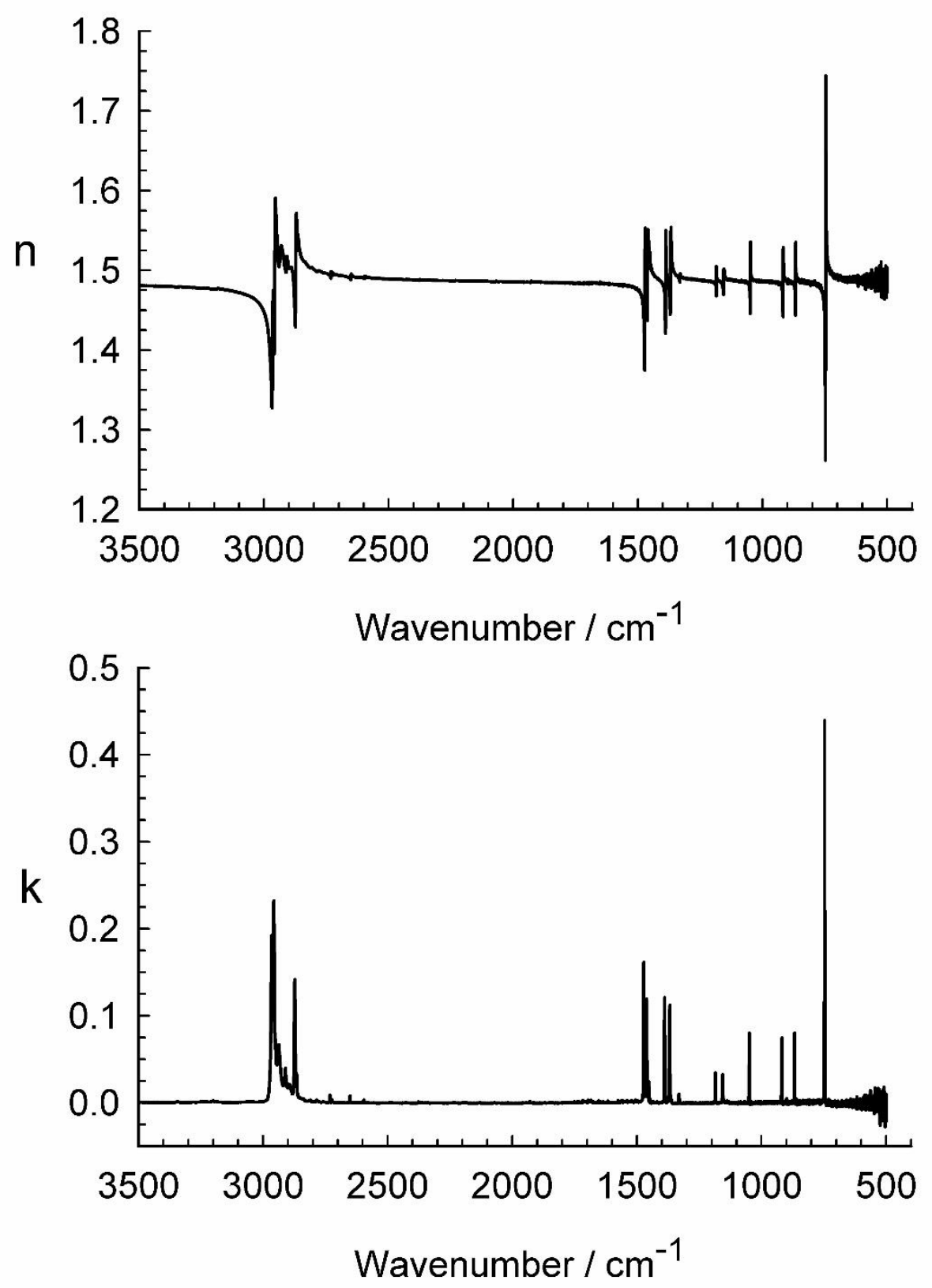

Fig. 14. Optical constants of the stable crystalline form of propane at $80 \mathrm{~K}$. 


\section{Discussion}

\subsection{Propane, propylene, and propyne IR spectra}

The IR spectra of propane in Figs. $\mathbf{1}$ - $\mathbf{4}$ are about as expected based on the literature already cited. Lab-to-lab variations make quantitative comparisons of intensities difficult, but our peak positions for propane are in reasonable agreement with earlier work, allowing for differences in temperature, sample preparation, and so on. The propane results that are closest to our own are those of Ghosh et al. (2018). Their paper's IR spectra show only the $\sim 3000-2830$ and $1520-1320 \mathrm{~cm}^{-1}$ regions, but there is close agreement with our Figs. 2 and 3 . However, since the spectra of Ghosh et al. were recorded by reflection off a metal substrate, which can alter relative intensities, a more direct comparison is difficult (e.g., Pacansky and England, 1986). Seen that way, our Figs. 1 - $\mathbf{4}$ appear to be the first IR transmission spectra of these forms of solid propane, all recorded from a single sample, and our Table 3 appears to be the first tabulation of peak positions of the metastable crystalline form of solid propane.

Comments similar to these also apply to our IR results for propylene ices. We are unaware of previous work showing spectra of the three solid phases reported here, all recorded in transmission with quantitative measurements of band and peak intensities. Moreover, we are unaware of any spectra of the metastable crystalline phase of propylene other than those presented here.

As with its smaller alkyne relation, acetylene $(\mathrm{HC} \equiv \mathrm{CH})$, propyne displayed only amorphous and crystalline solid forms (Hudson et al., 2014a). Unlike the cases of the two other $\mathrm{C}_{3}$ compounds in this paper, we were unable to find previous IR spectra of solid propyne. The liquid-phase Raman spectrum of Crawford (1940) bears some similarities to our infrared spectra, but comparisons are difficult other than for peak positions.

\subsection{Propane, propylene, and propyne ices}

Our observation of the formation of amorphous ices on slow deposition at cryogenic temperatures certainly is not new (Malherbe and Bernstein, 1951; Nightingale and Wagner, 1954). Our spectra of amorphous hydrocarbons show the usual characteristics, namely broad IR features resembling those of a liquid, and with peaks that sharpen, split, and shift when crystallization takes place on warming. As already mentioned, no difficulty was met in making amorphous forms of these $\mathrm{C}_{3}$ hydrocarbons, unlike with some $\mathrm{C}_{2}$ hydrocarbons in our earlier work (e.g., Hudson et al., 2014a; Hudson et al., 2014b).

The situation with our crystalline hydrocarbon ices is more complicated, with two crystalline phases being observed for both propane and propylene. In our studies of $\mathrm{CH}_{3} \mathrm{CN}$ and $\mathrm{CH}_{3} \mathrm{SH}$, two crystalline forms were expected and found for each compound, 
and our identifications of each phase were considerably helped by prior diffraction and spectroscopic results (Hudson, 2016; Hudson, 2020). Unfortunately, we have not found similar studies of either propane or propylene. The best we can do for our hydrocarbons' stable crystalline phases is again to note that the form we have labeled as crystalline phase II in each case was never seen to convert into the crystalline phase I form. Moreover, on heating propane and propylene ices until they melted and then recooling them, IR spectra of the phase II form were always obtained. These observations suggest that what we have designated as the phase II polymorphs of propane and propylene are indeed the stable forms at the temperatures indicated. These conclusions place our work in agreement with that of Ghosh et al. (2018). We also are in agreement with the earlier calorimetric study of Takeda et al. (1990) of the irreversible formation of two phases on warming amorphous propane and amorphous propylene.

In contrast, the situation with our metastable crystalline phase I forms is less clear, except that they convert into the phase II structures on warming. Returning again to our earlier studies, we found that warming amorphous $\mathrm{CH}_{3} \mathrm{CN}$ produced first the kinetically favored high-temperature crystalline phase of acetonitrile and not the thermodynamically and perhaps intuitively favored low-temperature phase, in agreement with the Ostwald step rule (Ostwald, 1897; Tizek et al., 2004). Here we suggest that amorphous propane and amorphous propylene might behave in a similar manner. What we have described as metastable hydrocarbon solids (phase I) forming on crystallization from amorphous ices, followed by stable forms (phase II) on additional warming, could be the result of a competition between kinetic and thermodynamic control as seen with amorphous $\mathrm{CH}_{3} \mathrm{CN}$ and $\mathrm{CH}_{3} \mathrm{SH}$ ices (Hudson, 2016; Hudson, 2020). Our IR results seem consistent with that as trace (c) in Fig. 2, for the metastable form (phase I) of propane, appears to more closely resemble the disordered amorphous-ice spectra of (a) and (b) than does trace (d) for phase II.

We also suggest that the adjectives "metastable" and "stable" for phases I and II, respectively, might need to be exchanged at higher temperatures, such as in a narrow region near the melting points of propane and propylene. This interpretation could also help reconcile the work of Pavese and Besley (1981), of two crystalline forms of propane near the compound's melting point, with the results presented here and by Takeda et al. (1990), and Ghosh et al. (2018). We and the latter two groups approached propane crystallization by warming an amorphous solid, but Pavese and Besley (1981) studied crystallization by starting with room-temperature liquid propane, also an amorphous material. Although it is difficult to compare stabilities and temperatures for solid-solid transitions between these two types of experiments, we suggest that our phases I and II might well correspond to phases $\beta$ and $\alpha$, respectively, of Pavese and Besley (1981), the differences in stability in the two types of experiment being due to differences in temperature and mode of formation.

Clearly, further study is needed to clarify this situation. Boese et al. (1999) summarized the results of earlier work on the next higher (i.e., butane) and lower (i.e., 
ethane) alkanes from propane, noting that an orientationally disordered phase of each exists just below the compound's melting point. Such may well be true of propane too.

Comments similar to those just made for propane's phases also apply to propylene. We know of no comparable work on solid propylene other than that already mentioned. It is interesting that both we and Takeda et al. $(1990,1991)$ find that crystallization of amorphous propane occurs on the order of $10 \mathrm{~K}$ lower than for amorphous propylene. Propane's symmetrical $\left(\mathrm{H}_{3} \mathrm{C}-\mathrm{CH}_{2}-\mathrm{CH}_{3}\right)$ arrangement of two $\mathrm{C}-\mathrm{C}$ single bonds about the central carbon suggests that the formation of a crystalline structure might well be more facile than for propylene $\left(\mathrm{H}_{2} \mathrm{C}=\mathrm{CH}-\mathrm{CH}_{3}\right)$, with a specific arrangement of $\mathrm{C}-\mathrm{C}$ and $\mathrm{C}=\mathrm{C}$ bonds needed to make a crystal. It would be interesting to test this interpretation by measuring the temperature regions for crystallization of amorphous propyne $\left(\mathrm{HC} \equiv \mathrm{C}-\mathrm{CH}_{3}\right)$ and its more-symmetrical isomer allene $\left(\mathrm{H}_{2} \mathrm{C}=\mathrm{C}=\mathrm{CH}_{2}\right)$. Crystallization of allene is predicted to occur at lower temperatures than for propyne.

\subsection{Applications and extensions}

The applications of our work are primarily to extraterrestrial environments at temperatures below about $90 \mathrm{~K}$. The amorphous forms of our pure hydrocarbons will be those expected at the lower temperatures, especially if, as is likely, these compounds are combined with more abundant materials. Our crystalline ices would seem to have less application, except perhaps to cases such as Titan where temperatures would permit crystallization. Hydrocarbon clouds dominated by methane $\left(\mathrm{CH}_{4}\right)$ and subject to magnetospheric bombardment, will produce more-complex hydrocarbons, including those examined here, and some will be at temperatures expected to lead to propane, propylene, and propyne ices.

We also should mention extensions of our results to other spectral regions. There are planetary-science observations that employ the near-IR region and interstellar work that uses far-IR wavelengths. Our mid-IR results sit in the middle of these two regions. The mid-IR band absorption coefficients and band strengths in our tables can readily be used as reference data to scale near- or far-IR spectral features and obtain intensity data for those regions. See Gerakines et al. (2005) and Giulano et al. (2014) for two examples.

Laboratory applications also are readily envisioned. Low-temperature in situ radiolysis work has been reported for the simpler hydrocarbons methane and ethane, and the formation of more-complex hydrocarbons has been found by IR spectroscopy. The data reported here allow for the first accurate quantification of such lowtemperature results, such as determinations of reaction yields and branching ratios. Simple photolytic or radiolytic oxidations (hydrogen loss) such as $\mathrm{C}_{3} \mathrm{H}_{8} \rightarrow \mathrm{C}_{3} \mathrm{H}_{6} \rightarrow \mathrm{C}_{3} \mathrm{H}_{4}$ can now be quantified. Conversely, starting with the simplest of these three hydrocarbons one can now quantify reductions such as $\mathrm{C}_{3} \mathrm{H}_{4} \rightarrow \mathrm{C}_{3} \mathrm{H}_{6} \rightarrow \mathrm{C}_{3} \mathrm{H}_{8}$ as well as conversions of $\mathrm{C}_{3} \mathrm{H}_{4}$ and $\mathrm{C}_{3} \mathrm{H}_{6}$ to make 3-carbon alcohols (e.g., Qasim et al., 2019). 
As for needs, several already have been mentioned. Certainly diffraction studies are needed for the solid phases of these compounds as are studies of the IR spectra in closed cells. It also would be useful to have better data on the IR spectra of the liquid forms of our hydrocarbons, and the degree to which supercooling can be detected remotely in the laboratory and on planetary surfaces. Our results also could be used to determine vapor pressures for our compounds, and perhaps enthalpies of sublimation (Khanna et al., 2005). Quantitative extensions of our spectral measurements to both shorter and longer wavelengths are needed, and should be straightforward now that our IR intensity data are available. Also, our optical constants will permit spectral simulations of hydrocarbon particles, such as in hazes, with variations in particle shape and size. Finally, the somewhat surprising formation and stability of liquid propane and liquid propylene in the $80 \mathrm{~K}$ region could open up new possibilities for liquid-phase measurements on these compounds of relevance to Titan, such as anticipating and interpreting results of NASA's Dragonfly mission. Given the complexity and costs of planetary missions, laboratory studies will continue to play a role in unraveling Solar System chemistry.

\section{Acknowledgments}

NASA funding through the Cassini Data Analysis Program is acknowledged, as is support from NASA's Planetary Science Division Internal Scientist Funding Program through the Fundamental Laboratory Research (FLaRe) work package at the NASA Goddard Space Flight Center. YYY thanks the NASA Postdoctoral Program for her fellowship. Marla Moore (NASA, retired), Robert Ferrante (US Naval Academy), and Mark Loeffler (Northern Arizona University) contributed to various stages of this work.

\section{References}

Baratta, G. A., Domingo, M., Ferini, G., Leto, G., Palumbo, M. E., Satorre, M. A., Strazzulla, G., 2003. Ion irradiation of $\mathrm{CH}_{4}$-containing icy mixtures. Nucl. Instru. Meth. Phys. Res. B 209, 283-287.

Behmard, A., Fayolle, E. C., Graninger, D. M., Bergner, J. B., Martín-Doménech, R., Maksyutenko, P., Rajappan, M., Öberg, K. I., 2019. Desorption kinetics and binding energies of small hydrocarbons. Astrophys. J. 875, 1.

Bennett, C. J., Jamieson, C. S., Osamura, Y., Kaiser, R. I., Laboratory studies on the irradiation of methane in interstellar, cometary, and solar system ices. Astrophys. J. 2006, 653, 792-811.

Boese, R., Weiss, H., Bläser, D., 1999. The melting point alternation in the short-chain $n$-alkanes: Single-crystal X-ray analyses of propane at $30 \mathrm{~K}$ and of $n$-butane to $n$ nonane at $90 \mathrm{~K}$. Angew. Chem. Int. Ed. 38, 988-992. 
Bol'shutkin, D. N., Gasan, V. M., Prokhvatilov, A. I., 1971. Temperature dependence of parameter of a methane crystal lattice in a temperature range from 11 - 70 degrees $\mathrm{K}$. Zhurnal Strukturnoi Khimii 12, 734-736.

Brann, M. R., Thompson, R. S., Sibener, S. J., 2020. Reaction kinetics and influence of film morphology on the oxidation of propene thin films by $\mathrm{O}\left({ }^{3} \mathrm{P}\right)$ atomic oxygen. J. Phys. Chem. A. 124, 7205-7215.

Brown, M. E., Schaller, E. L., Blake, G. A., 2015. Irradiation products on dwarf planet Makemake. Astron. J. 149, 1-6.

Coustenis, A., Schmitt, B., Khanna, R. K., Trotta, F., 1999. Plausible condensates in Titan's stratosphere from Voyager infrared spectra. Planet. Sp. Sci. 47, 1305-1329.

Crawford Jr., B. L., 1940. Infra-red and Raman spectra of polyatomic molecules. XII. Methyl acetylene. J. Chem. Phys. 8, 526-531.

Cruikshank, D. P., Dalle Ore, C. M., Clark, R. N., Pendleton, Y. J., 2014. Aromatic and aliphatic organic materials on lapetus: Analysis of Cassini VIMS data. Icarus 233, 306315.

Cruikshank, D. P., Grundy, W. M., DeMeo, F. E., Buie, M. W., et al., 2015. Icarus 246, 82-92.

Dartois, E., Chabot, M., Pino, T., Béro, K., Godard, M., Severin, D., Bender, M., Trautmann, C., 2017. Swift heavy ion irradiation of interstellar dust analogues - Small carbonaceous species released by cosmic rays. Astron. \& Astrophys. 599, 1.

de Barros, A. L. F., Bordalo, V., Seperuelo Duarte, E., da Silveira, E. F., Domarack, A., Rothard, H., Boduch, P., 2011. Cosmic ray impact on astrophysical ices: Laboratory studies on heavy ion irradiation of methane. Astron. \& Astrophys. 513, 1-9.

De Sanctis, M. C., Ammannito, E., McSween, H. Y., et al., 2017. Localized aliphatic organic material on the surface of Ceres. Science 355, 719-722.

Enjalbert, R., Galy, J., 2002. $\mathrm{CH}_{3} \mathrm{CN}$ : X-ray structural investigation of a unique single crystal. $\beta \rightarrow \alpha$ phase transition and crystal structure. Acta Cryst. B58, 10051010.

Fleury, B., Gudipati, M. S., Couturier-Tamburelli, I., Carrasco, N., 2019. Photoreactivity of condensed acetylene on Titan aerosols analogues. Icarus 321, 358-366.

Gerakines, P. A., Bray, J. J., Davis, A., Richey, C., 2005. The strengths of near-infrared absorption features relevant to interstellar and planetary ices. Astrophys. J. 620, 11401150. 
Gerakines, P. A., Hudson, R. L., 2020. A modified algorithm and open-source computational package for the determination of infrared optical constants relevant to astrophysics. Manuscript in preparation.

Gerakines, P. A., Schutte, W. A., Ehrenfreund, P., 1996. Ultraviolet processing of interstellar ice analogs. I. Pure ices. Astron. \& Astrophys. 312, 289-305.

Ghosh, J., Hariharan, A. K., Bhuin, R. G., Methikkalam, R. R. J, Pradeep, T., 2018. Propane and propane-water interactions: A study at cryogenic temperatures. Phys. Chem. Chem. Phys. 20, 1838-1847.

Giulano, B. M., Escribano, R. M., Martin-Doménech, R., Dartois, Muñoz Caro, G. M., 2014. Interstellar ice analogs: Band strengths of $\mathrm{H}_{2} \mathrm{O}, \mathrm{CO}_{2}, \mathrm{CH}_{3} \mathrm{OH}$, and $\mathrm{NH}_{3}$ in the farinfrared region. Astron. \& Astrophys. 565, A108

Goodman, M. A, Sweany, R. L., Flurry Jr., R. L., 1983. Infrared spectra of matrixisolated, crystalline solid, and gas-phase $\mathrm{C}_{3}-\mathrm{C}_{6} \mathrm{n}$-Alkanes. J. Phys. Chem. 87, 17531757.

Gough, K. M., Murphy, W. F., Raghavachari, K., 1987. The harmonic force field of propane. J. Chem. Phys. 87, 3332-3340.

Hollenberg, J. L., Dows, D. A., 1961. Measurement of absolute infrared absorption intensities in crystals. J. Chem. Phys. 34, 1061-1063.

Hudson, R. L., 2016. Infrared spectra and band strengths of $\mathrm{CH}_{3} \mathrm{SH}$, an interstellar molecule. Phys. Chem. Chem. Phys. 18, 25756-25763.

Hudson, R. L., 2020. Preparation, identification, and low-temperature infrared spectra of two elusive crystalline nitrile ices. Icarus 338, 113548.

Hudson, R. L., Ferrante, R. F., Moore, M. H., 2014a. Infrared spectra and optical constants of astronomical ices: I. Amorphous and crystalline acetylene. Icarus 228, 276-287.

Hudson, R. L., Gerakines, P. A., Moore, M. H., 2014b. Infrared spectra and optical constants of astronomical ices: II. Ethane and ethylene. Icarus 243, 148-147.

Hudson, R. L., Loeffler, M. J., Gerakines, P. A., 2017. Infrared spectra and band strengths of amorphous and crystalline $\mathrm{N}_{2} \mathrm{O}$. J. Chem. Phys. 146, 0243304.

Hudson, R. L., Moore, M. H., Raines, L. L., 2009. Ethane ices in the outer solar system: Spectroscopy and chemistry. Icarus 203, 677-680. 
Khanna, R. K., Allen Jr., J. E., Masterton, C. M., Zhao, G., 1990. Thin-film infrared spectroscopic method for low-temperature vapor-pressure measurement. J. Phys. Chem. 94, 440-442.

Loerting, T., Bauer, M., Kohl, I., Watschinger, K., Winkel, K., Mayer, E., 2011. Cryoflotation: Densities of amorphous and crystalline ices. J. Phys. Chem. B. 115, 14167-14175.

Luna, R. Satorre, M. Á., Domingo, M., Millán, C., Santonja, C., 2012. Density and refractive index of binary $\mathrm{CH}_{4}, \mathrm{~N}_{2}$ and $\mathrm{CO}_{2}$ ice mixtures. Icarus 221, 186-191.

Maass, O., Wright, C. H., 1921. Some physical properties of hydrocarbons containing two and three carbon atoms. J. Amer. Chem. Soc. 43, 1098-1011.

Maeda, S., Schatz, P. N., 1961. Absolute infrared intensity measurements in thin films. J. Chem. Phys. 35, 1617-1620.

Maguire, W. C., Hanel, R. A., Jennings, Kunde, V. G., Samuelson, R. E., 1981. $\mathrm{C}_{3} \mathrm{H}_{8}$ and $\mathrm{C}_{3} \mathrm{H}_{4}$ in Titan's atmosphere. Nature 292, 683-686.

Malherbe, F. E., Bernstein, H. J., 1951. Infrared spectra of rapidly solidified vapors. J. Chem. Phys. 19, 1607-1608.

Marcelino, N., Cernicharo, J. Agúndez, M., Roueff, E., Gerin, M., Martín-Pintado, J., Mauersberger, R., Thum, C., 2007. Discovery of interstellar propylene $\left(\mathrm{CH}_{2} \mathrm{CHCH}_{3}\right)$ : Missing links in interstellar gas-phase chemistry. Astrophys. J. 665, L127-L130.

Mejía, C. F., de Barros, A. L. F., Bordalo, V., da Silveira, E. F., Boduch, P., Domaracka, A., Rothard, H., 2013. Cosmic ray-ice interaction studied by radiolysis of $15 \mathrm{~K}$ methane ice with $\mathrm{MeV} \mathrm{O}, \mathrm{Fe}$ and $\mathrm{Zn}$ ions. MNRAS 433, 2368-2379.

Mizuno, Y., Kofu, M., Yamauro, O., 2016. X-ray diffraction study on simple molecular glasses created by low-temperature vapor deposition. J. Phys. Soc. Japan 85, 124602.

Moore, M. H., Hudson, R. L., 1998. Infrared study of ion-irradiated water-ice mixtures with hydrocarbons relevant to comets. Icarus 135, 518-527.

Moore, M. H., Ferrante, R. F., Moore, W. J., Hudson, R., 2010. Infrared spectra and optical constants of nitrile ices relevant to Titan's atmosphere. Astrophys. J. Suppl. Ser. 191, 96-112.

Nightingale, R. E., Wagner, E. L., 1954. The vibrational spectra and structure of solid hydroxylamine and deutero-hydroxylamine. J. Chem. Phys. 22, 203-208. 
Nixon, C. A., Jennings, D. E., Bézard, B., Vinatier, S., Teanby, N. A., Sung, K., Ansty, T. M., Irwin, P. G. J., Gorius, N., Cottini, V., Coustenis, A., Flasar, F. M., 2013. Detection of propene in Titan's stratosphere. Astrophys. J. 776, L14.

Ostwald, W., 1897. Studien über die Bildung und Umwandlung fester Körper. Z. Phys. Chem. 22, 289-330.

Pacansky, J., England, C. D., 1986. Analysis of infrared specular reflection spectroscopy of rare-gas matrices. J. Chem. Phys. 90, 4499-4508.

Pavese, F., Besley, L. M., 1981. Triple-point temperature of propane: Measurements on two solid-to-liquid transitions and one solid-to-solid transition. J. Chem. Thermo. 13, 1095-1104.

Qasim, D., Fedoseev, G., Lamberts, T., Chuang, K., He, J., loppolo, S., Kästner, J., Linnartz, $\mathrm{H}$., 2019. Alcohols on the rocks: Solid-state formation in a $\mathrm{H}_{3} \mathrm{CC} \equiv \mathrm{CH}+\mathrm{OH}$ cocktail under dark cloud conditions. ACS Earth Space Chem. 209, 986-999.

Raponi, A. Ciarniello, M., Capaccioni, F., et al., 2020. Infrared detection of aliphatic organics on a cometary nucleus. Nature Astronomy 4, 500-505.

Roe, H. G., Greathouse, T. K., Richter, M. J., Lacy, J. H., 2003. Propane on Titan. Astrophys. J. 597, L65-L68.

Romanescu, C., Marschall, J., Kim, D., Khatiwada, A., Kalogerakis, K. S., 2010. Refractive index measurements of ammonia and hydrocarbon ices at $632.8 \mathrm{~nm}$. Icarus 205, 695-701.

Sasaki, T., Kanno, A., Ishiguro, M., Kinoshita, D., Nakamura, R., 2005. Search for nonmethane hydrocarbons on Pluto. Astrophys. J. 618, L57-L60.

Sephton, M. A., Pillinger, C. T., Gilmour, I., 2001. Normal alkanes in meteorites: Molecular $\delta^{13} \mathrm{C}$ values indicate an origin by terrestrial contamination. Precambrian Res. 106, 45-58.

Silvi, B., Labarbe, P., Perchard, J. P., 1973. Spectres de vibration et coordonnées normales de quatre espèces isotopiques de propène. Spectrochim. Acta 29A, 263-276.

Snyder, L. E., Buhl, D., 1973. Interstellar methylacetylene and isocyanic acid. Nature Phys. Sci. 243, 45-56.

Snyder, R. G., Schachtschenider, J. H., 1963. Vibrational analysis of the n-paraffins - I Assignments of infrared bands in the spectra of $\mathrm{C}_{3} \mathrm{H}_{8}$ through $\mathrm{n}-\mathrm{C}_{19} \mathrm{H}_{40}$. Spectrochim. Acta 19, 85-116.

Strazzulla, G., Calcagno, L., Foti, G., 1984. Build up of carbonaceous material by fast protons on Pluto and Triton. Astron. \& Astrophys. 140, 441-444. 
Swanepoel, R., 1983. Determination of the thickness and optical constants of amorphous silicon. J. Phys. E: Sci. Instrum. 16, 1214-1222.

Takeda, K, Oguni, M., Suga, H., 1990. A DTA apparatus for vapour-deposited samples. Characterisation of some vapour-deposited hydrocarbons. Thermochim. Acta 158, 195203.

Takeda, K, Oguni, M., Suga, H., 1991. Thermo-analytical study of vapor-deposited $n$ alkanes. J. Phys. Chem. Solids 52, 991-997.

Teanby, N. A., Irwin, P. G. J., de Kok, R., Jolly, A., Bézard, B., Nixon, C. A., Calcutt, S. B., 2009. Titan's stratospheric $\mathrm{C}_{2} \mathrm{~N}_{2}, \mathrm{C}_{3} \mathrm{H}_{4}$, and $\mathrm{C}_{4} \mathrm{H}_{2}$ abundances from Cassini/CIRS far-infrared spectra. Icarus 202, 620-631.

Tempelmeyer, K. E., Mills, D. W., 1968. Refractive index of carbon dioxide cryodeposit. J. Appl. Phys. 39, 2968-2969.

Tizek, H., Grothe, H., Knözinger, E., 2004. Gas-phase deposition of acetonitrile: An attempt to understand Ostwald's step rule on a molecular basis. Chem. Phys. Lett. 383, 129-133.

Tomlin, S. G., 1968. Optical transmission and reflection formulae for thin films. Brit. J. Appl. Phys. (J. Phys. D) 2, 1667-1671.

Torrie, B. H., Binbrek, O. S., Strauss, M., Swainson, I. P., 2002. Phase transitions in solid methanol. J. Sol. State Chem. 166, 415-420.

Vasconcelos, F. A., Pilling, S., Rocha, W. R. M., Rothard, H., Boduch, P., Ding, J. J., 2017. Ion irradiation of pure and amorphous $\mathrm{CH}_{4}$ ice relevant for astrophysical environments. Phys. Chem. Chem. Phys. 19, 12845-12856.

Whitmer, J. C., 1974. Normal coordinate and potential energy distributions of methyl acetylene and some halogen substituted analogues. J. Molec. Struct. 21, 173-183. 